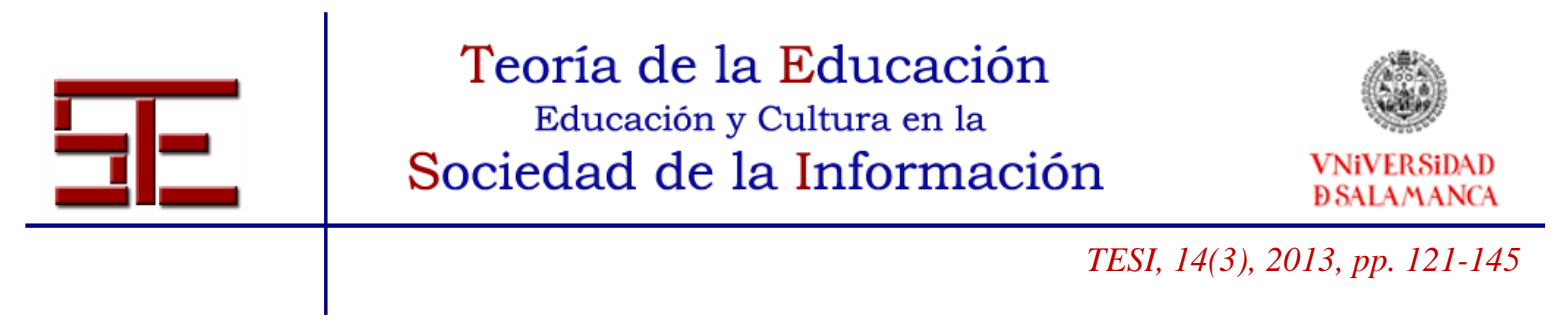

\title{
APROXIMACIÓN ÉTICA A LA COMPETENCIA DIGITAL. LOS NIVELES DE USO Y SENTIDO EN ÁMBITOS EDUCATIVOS VIRTUALES
}

Resumen: En el contexto del ciberespacio y las tecnologías, ¿debemos hacer todo lo que podemos hacer?. La respuesta que se da a esta cuestión no es ética sino de tipo político: seguridad. De forma segura puede hacerse todo. La seguridad y la protección están eclipsando sin embargo la pregunta ética por el sentido de la tecnología. El ciberespacio impone una "nueva lógica" y nuevas formas de "apropiación". Cuando nos referimos a internet en relación con la infancia no siempre adoptamos una lógica de responsabilidad ante el ciberespacio, mostrando internet como un espacio ético y no sólo técnico, de posibilidades. Hablamos de internet seguro, internet saludable, internet apropiado para los niños... ¿porqué no hablar más de ética en internet?.

Con este trabajo tratamos de aproximarnos las competencias digitales como aquellas competencias que nos ayudan a situarnos y orientarnos en el ciberespacio. Algo que no es posible sin contar también con ciertas competencias éticas. Así, en este artículo trataremos de construir y proponer un modelo de análisis de los espacios formativos virtuales (y del ciberespacio en general) basado en las categorías de "uso" y "sentido" como diferentes niveles y lógicas de apropiación que nos indican los tipos de competencia necesarios para acceder al ciberespacio.

Palabras clave: competencia digital; competencia ética; ciberespacio; tecnología educativa.

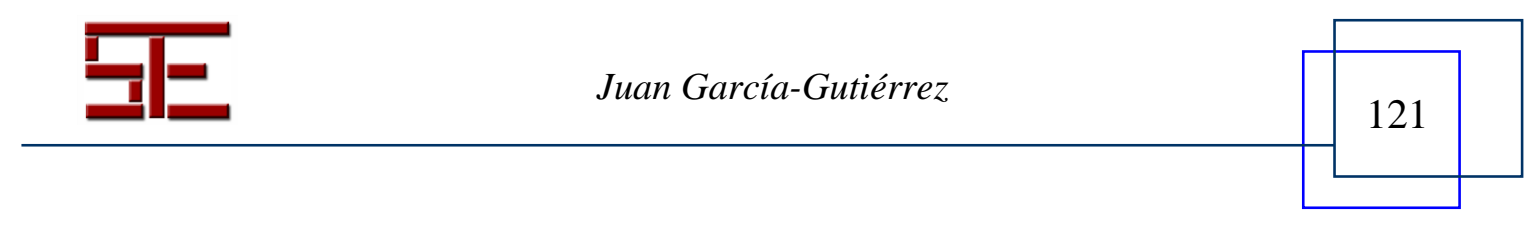




\title{
ETHICAL APPROACH TO DIGITAL SKILLS. SENSE AND USE IN VIRTUAL EDUCATIONAL SPACES
}

\begin{abstract}
In the context of technology and cyberspace, should we do everything we can do? The answer given to this question is not ethical, is political: safety. The safety and security are overshadowing the ethical question about the meaning of technology. Cyberspace imposes a "new logic" and new forms of "ownership". When it comes to the internet in relation to children not always adopt a logic of accountability to the cyberspace, internet showing a space not only ethical and technical. We talk about safe internet, internet healthy, internet Fit for Children... why not talk over internet ethics?.

With this work we approach digital skills as those skills that help us to position ourselves and guide us in cyberspace. Something that is not possible without also ethical skills. So, in this article we will try to build and propose a model for analyzing the virtual learning spaces (and cyberspace in general) based on the categories of "use" and "sense" as different levels of ownership that indicate the types of competences needed to access cyberspace.
\end{abstract}

Key words: digital skills; ethical skills; cyberspace; educational technology.

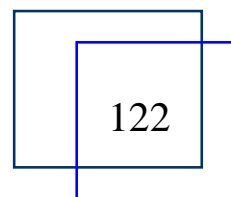




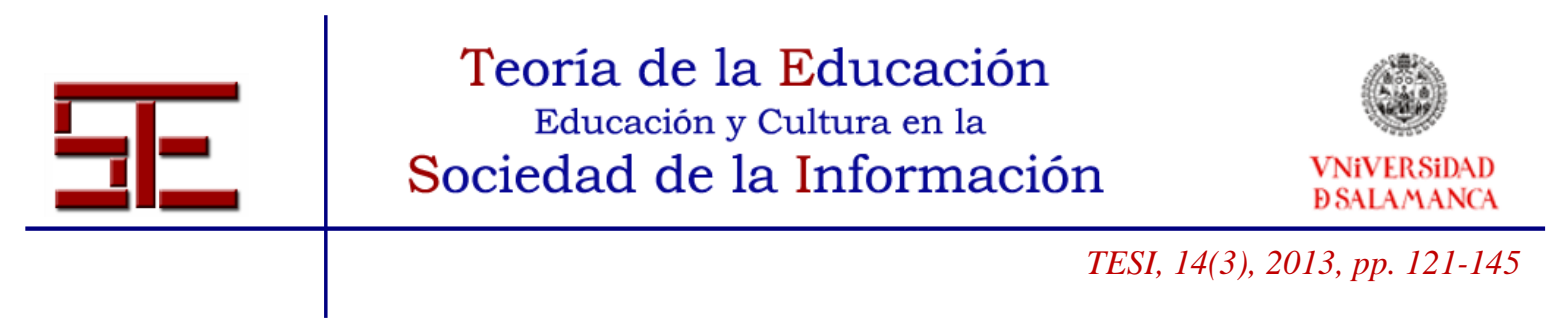

\title{
APROXIMACIÓN ÉTICA A LA COMPETENCIA DIGITAL. LOS NIVELES DE USO Y SENTIDO EN ÁMBITOS EDUCATIVOS VIRTUALES
}

Fecha de recepción: 08/07/2013; fecha de aceptación: 16/09/2013; fecha de publicación: 30/11/2013

\author{
Juan García-Gutiérrez \\ juangarcia@edu.uned.es \\ Universidad Nacional de Educación a Distancia
}

\begin{abstract}
"Entendemos que el objetivo propio de la formación permanente en nuestros días radicará no tanto en proporcionar una oportunidad para conocer los últimos avances de la propia profesión, cuanto en despertar la curiosidad hacia esas otras zonas del saber que por la temprana especialización han quedado preteridas, y en fomentar las actitudes y proporcionar los conocimientos que permitan al espíritu del hombre estar abierto a la totalidad de lo real"
\end{abstract}

J. A. Ibáñez-Martín, Hacia una formación humanística

\section{DE LA SEGURIDAD A LA ÉTICA EN EL CIBERESPACIO}

Según datos de la Unión Europea, el $75 \%$ de los niños de edad comprendida entre 6 y 17 años en Europa utilizan internet. Los de 15 y 16 años manifiestan haberse conectado por vez primera a los 11. En comparación, los de 9 y 10 años indican que, por término medio, comenzaron a utilizarla a los 7 . El $33 \%$ de los niños de 9 a 16 años que usan Internet dicen hacerlo desde un teléfono móvil u otro dispositivo portátil. ${ }^{19}$ Por otra parte, la lectura económica de la tecnologia tampoco es ajena al ámbito de la infancia,

\begin{abstract}
"Prestar atención a las demandas de los niños abre un amplio abanico de oportunidades para las empresas. Se prevé que el mercado mundial de contenidos digitales rebase los 113000 millones EUR en 2012. El valor de mercado de las aplicaciones móviles asciende a 5000 millones EUR, y se espera que alcance los 27000 millones en 2015, impulsado principalmente por los juegos y con más de 5000 millones de abonados a la telefonía móvil en el mundo. En cuanto al mercado mundial de los juegos de vídeo, se espera que sus ventas rebasen los 62000 millones EUR. Con la proliferación de tabletas, teléfonos inteligentes y ordenadores portátiles que los menores utilizan intensamente, existe un importante mercado potencial de contenidos creativos y educativos en línea e interactivos para niños y adolescentes. Las aplicaciones y los juegos móviles y en línea ofrecen oportunidades de desarrollo empresarial sin precedentes, en particular para las PYME y los creadores, ya que permiten un contacto directo con usuarios/clientes potenciales. Los propios niños podrían convertirse en creadores en línea e iniciar una actividad empresarial" (Comisión Europea, 2012).
\end{abstract}

Tanto internet como las TIC ofrecen a los niños plataformas desde donde pueden jugar, aprender, relacionarse y socializarse. Dadas sus características de "minoría de edad" y

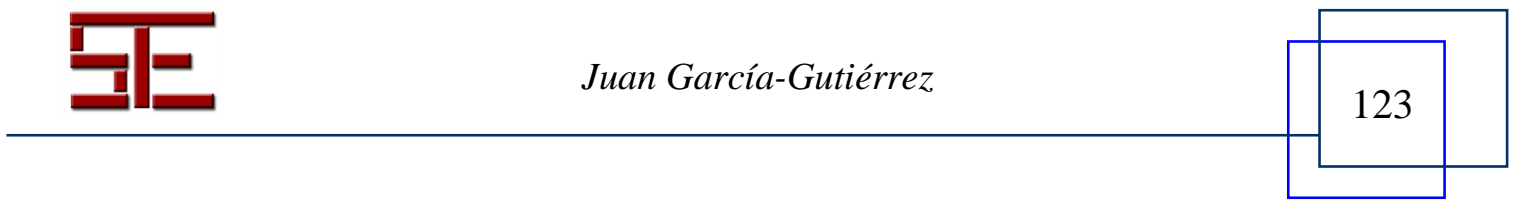




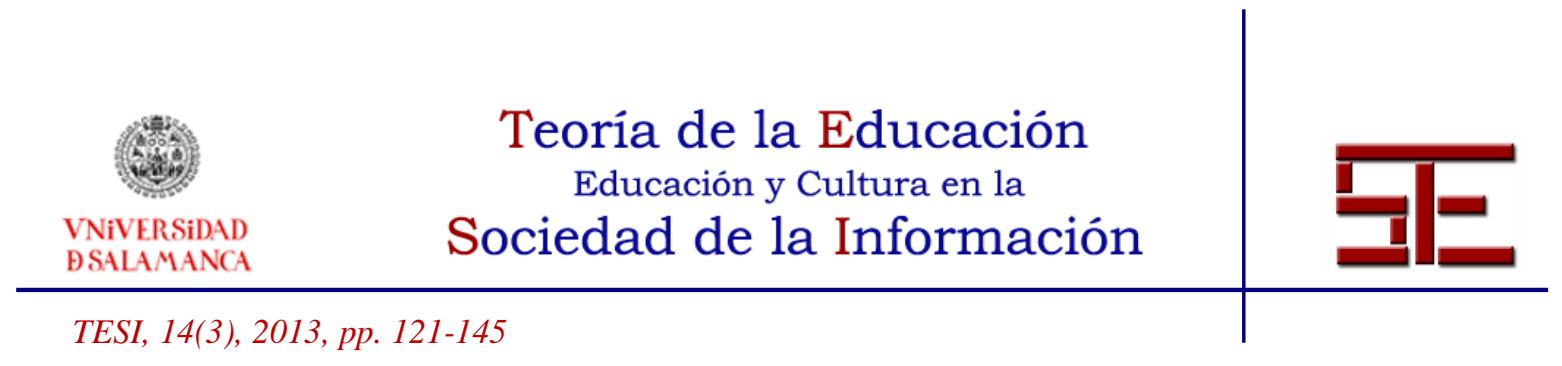

"evolución de sus capacidades", constituye un grupo con necesidades formativas especialmente sensible al uso de la tecnología. Los datos expuestos anteriormente ponen de manifiesto el potencial y el impacto de la tenología en el ámbito de la infancia, algo sin duda a revisar desde una perspectiva pedagógica.

Por otra parte, en la literatura sobre internet han aparecido sucesivamente diferentes metáforas que nos ayudaban a comprender su significado, así como su alcance y aplicaciones (Gómez Cruz, 2007). En el ámbito educativo han hecho referencia a la biblioteca, la imprenta o como canal de comunicación (Adell, 2004). Nos gustaría destacar la metáfora de la "navegación" donde Innerarity (2013) contrapone tierra y mar, y donde muestra el importante papel que juega la figura del "pirata". En efecto, para Innerarity, la idea de piratería nos ayuda a enfocar muchos de nuestros conflictos actuales en torno a los modos en que las ideas y las tecnologías son creadas, distribuidas y usadas. La idea que subyace a la matáfora marítima es que en el mar las nociones de propiedad y soberanía quedan diluidas; al contrario de lo que pasa en tierra, donde soberanía y propiedad rigen las relaciones entre personas y pueblos. Con el objetivo de escapar a una noción de soberanía expansiva, Hugo Grocio, en pleno siglo XVII, justifica el "derecho de presa" como una "nueva lógica marina" poniendo en cuestión así las aspiraciones de los estados soberanos de "apropiarse" de los mares; esto es, en nombre del derecho natural nadie puede apropiarse ni del mar ni del agua y es que es imposible apropiarse del mar, pues pertenede a todos (Innerarity, 2013).

Siguiendo esta terminología, podemos decir que los jóvenes actuales, "generación internet", pertenecen al médio líquido. En la metafora marítima resultaba fundamental la libertad de circulación y la desregulación en el intercambio de mercancías. Igualmente, el ciberespacio también impone una "nueva lógica" y nuevas formas de “apropiación”. Como médio líquido no sólo diluye conceptos y categorías tradicionales en la filosofía política (lógicas basadas en el territorio, la propiedad, la residencia, la identidad, etc.), sino que también puede afectar a la esfera moral y a las categorías éticas que aparecen eclipsadas por el uso y las posibilidades de la tecnología. Y es que a la sombra de la innovación o de la tecnología siempre aparecerá la pregunta por el sentido, ¿debemos hacer todo lo que podemos hacer?

La respuesta que se ofrece tiene que ver con la seguridad. La seguridad y la protección están eclipsando la pregunta ética por el sentido de la tecnología. La cuestión no es tanto un "internet seguro" cuanto la formación ética de las personas que usan internet. Parece que se pretende hurtar la responsabilidad sobre las propias acciones antes de actuar. Sin embargo, un uso seguro no es un uso ético. Aunque ante la proliferación de piratas en todos los órdenes sociales existe un interés creciente por la seguridad y la protección en detrimento de la libertad y la responsabilidad.

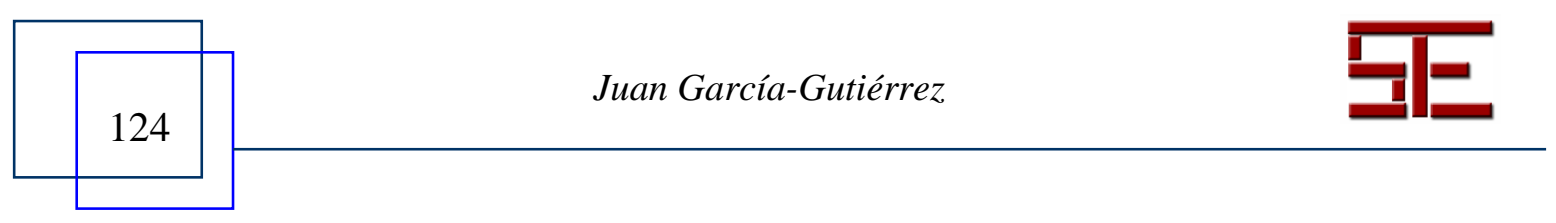




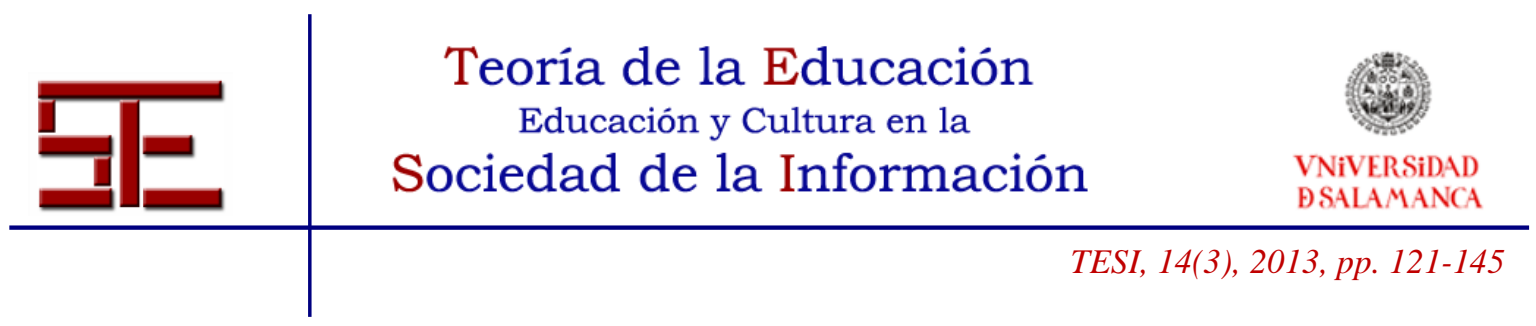

Desde un punto de vista pedagógico (y aunque es positiva la preocupación por la seguridad y la protección) resulta más congruente intervenir sobre las nociones de autonomía y responsabilidad en el ciberespacio (Reyero García, et. al, 2011). Sin embargo, cuando nos referimos a internet en relación con la infancia no siempre adoptamos una lógica de responsabilidad, mostrando internet como un espacio ético y no sólo técnico. No sólo es preciso la seguridad ${ }^{20}$ (es algo la mayor parte de las veces externo al sujeto) sino entender también el ciberespacio como un horizonte para la elaboración de sentidos. Hablamos de internet seguro, internet saludable, internet apropiado para los niños ${ }^{21} \ldots$ ¿porqué no hablar más de ética en internet?

Con este trabajo tratamos de aproximarnos las competencias digitales como aquellas competencias que nos ayudan a situarnos y orientarnos en el ciberespacio. Algo que no es posible sin contar también con las competencias éticas. Así, en este artículo trataremos de construir y proponer un modelo de análisis de los espacios formativos virtuales (y del ciberespacio en general) basado en las categorías de "uso" y "sentido" como diferentes lógicas y niveles de apropiación que nos indican los tipos de competencia necesarios para acceder al ciberespacio. ${ }^{22}$

En este sentido, partimos una hipótesis inicial sobre educación y ciberespacio; y es que la competencia digital (por ser una competencia educativa) no puede reducirse al ámbito instrumental, no es mero adiestramiento en dispositivos o programas con una orientación laboral (uso); también supone un núcleo ético que es necesario descifrar y asimilar (sentido) y que tiene que ver con el pleno desarrollo de la personalidad humana y su apertura a la totalidad de lo real.

\section{UNA APROXIMACIÓN A LA NOCIÓN DE COMPETENCIA}

\section{1. La preocupación educativa europea por el desarrollo de competencias}

La preocupación de la Unión Europa por la educación y la formación vinculada al empleo es indudable. El termino "competencia" nos ha llegado al terreno educativo directamente del ámbito laboral. Desde esta perspectiva, es necesario identificar y definir el perfil de los puestos de trabajo, así como fijar las competencias necesarias para desempeñarlo adecuadamente. En este contexto las instituciones educativas (según corresponda) se encargarían de llevar a cabo este tipo de formación. Veamos cómo se expresa esta preocupación en el contexto europeo:

\footnotetext{
“Ante la ampliación de la UE, con una población que envejece, emigración en aumento, carreras profesionales cada vez más complejas y mayores niveles de desempleo, todo ello con el riesgo asociado de la exclusión social, los países europeos han empezado a observar más de cerca aquellas competencias clave que los adultos pueden necesitar en el futuro. Las acciones no se deben limitar a definir e identificar las competencias clave necesarias. Se deben ampliar hasta determinar también cómo y dónde se han de enseñar estas competencias para garantizar que todos
}

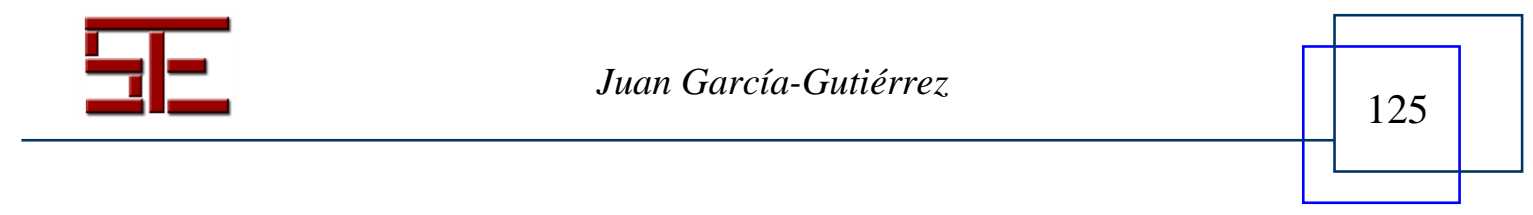




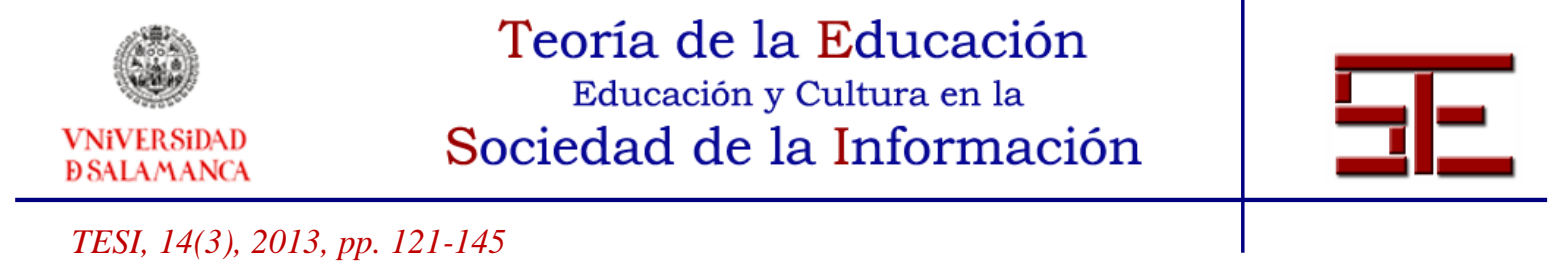

\begin{abstract}
los ciudadanos tengan acceso a su enseñanza. Existe una preocupación creciente en los países europeos de que sus ciudadanos identifiquen los conocimientos, las destrezas, competencias y actitudes que les permitirán tener un papel activo en esta sociedad regida por el conocimiento (...) Un punto de interés especial en este debate es la relación entre la economía y la educación básica. La eficacia de la última para preparar a los jóvenes para una integración económica y social apropiada está siendo cuestionada" (Eurydice, 2002, 11).
\end{abstract}

Entendemos con Marina $(2009,52)$ que éste enfoque de la competencia es el que ha pasado a la educación, dentro de una reformulación del proyecto político europeo. ${ }^{23}$ Proyecto político (y por tanto, en cierta forma, también educativo) ahogado en la llamada "estrategia de Lisboa", que tenía (y tiene) como objetivo "convertir la economía de la Unión en la economía del conocimiento más competitiva y dinámica del mundo". 24

La traducción educativa de esta "estrategia económica" se plasmó un año más tarde, en el Consejo Europeo de Estocolmo de 2001, con la aprobación del "Informe sobre los futuros objetivos precisos de los sistemas de educación y formación", 25 y el "Programa de trabajo para el seguimiento de los objetivos concretos de los sistemas de educación y formación en Europa". ${ }^{26}$ Este es el horizonte que se dibujaba y que "permitiría a todos los ciudadanos europeos participar en la nueva sociedad del conocimiento". ${ }^{27}$ Más adelante en 2006 aparecería la recomendación del Parlamento Europeo y el Consejo sobre las competencias clave para el aprendizaje permanente. ${ }^{28}$

Por otra parte, no podríamos hacer una lectura completa de la "estrategia (educativa) de Lisboa" sin tener en cuenta el ámbito de la formación, en una triple perspectiva: la apuesta por la mejora de la empleabilidad y la reducción de las deficiencias en materia de cualificaciones; conceder una mayor importancia de la formación continua; y por último, establecer un marco de referencia europeo para definir nuevas cualificaciones básicas. ${ }^{29}$ A ello colabora el "proceso de Copenhague" con el "Marco de referencia europeo de garantía de la calidad de la educación y la formación profesionales, y el "marco europeo de referencia para las cualificaciones". ${ }^{30}$

Para completar este breve recorrido sobre la implantación de la noción de competencia en todos los ámbitos educativos, tenemos que mirar también al ámbito universitario. En efecto, el proceso de Bolonia ha supuesto la introducción de las competencias en la enseñanza superior. Así, el diseño de las titulaciones por competencias no sólo genera un Espacio Europeo de Educación Superior (razonable trasposición de la libertad de circulación de personas, bienes y servicios), sino que se aproximan entre sí perfiles profesionales y titulaciones, de acuerdo a las demandas del mercado laboral.

Entre otros, la noción de competencia, en el ámbito universitario, implica también un cambio en la orientación tradicional de las relaciones entre universidad y empresa. Por

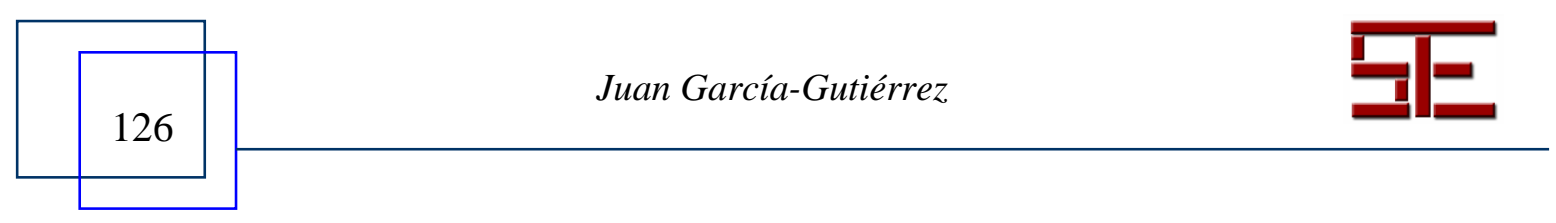




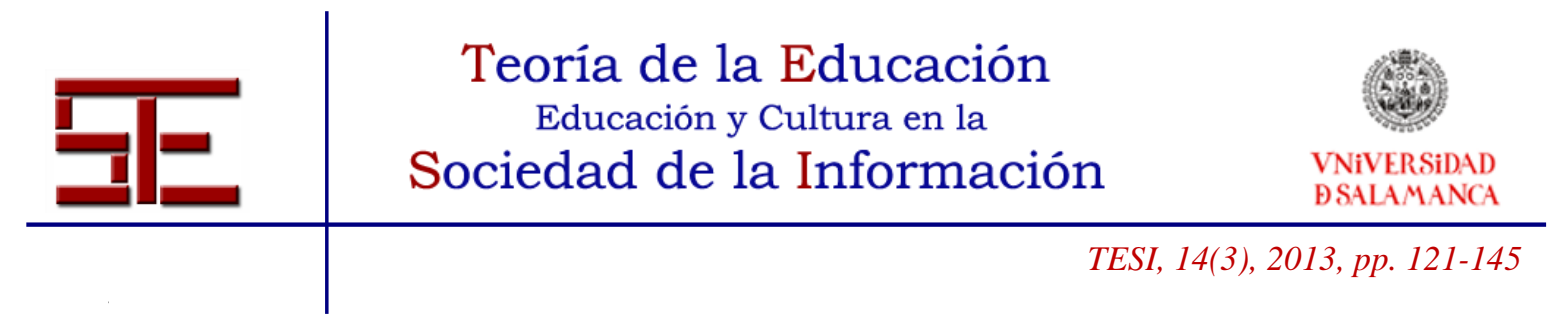

ejemplo, el proyecto "Tuning Education Structures in Europe" (de la Universidad de Deusto, entre otras) comenzó en 2000 como un proyecto para ligar los objetivos políticos del Proceso de Bolonia y de la Estrategia de Lisboa al sector educativo superior. ${ }^{31}$ Es el ámbito laboral quien define las necesidad de unos perfiles profesionales u otros. En este sentido, el proceso de adaptación de las titulaciones universitarias al EEES (y en concreto, en la elaboración de los libros blancos de ANECA para Pedagogía y Educación Social) ha contado con la participación de Asociaciones y Colegios profesionales, el estudio de la inserción laboral de los titulados y el estudio prospectivo de perfiles profesionales. ${ }^{32}$

\section{2. ¿Es posible encontrar un núcleo humanista en la educación en competencias?}

Como hemos visto hasta ahora, las organizaciones y administraciones educativas (nacionales e internacionales) han inundado el discurso educativo con la noción de competencia, lo que ha supuesto una importante producción científica sobre su estudio y evaluación, desde perspectivas diversas (Rychen D.S. y Salganik L.H., 2004; Navío Gámez, A. 2005; Attewell, P., 2009; Juanas, A., 2010; Ortega Navas, Ma . C. 2010; Bautista-Cerro, Ma J. y Melendro Estefanía, M., 2011).

En el siguiente cuadro se recogen algunas de las definiciones más relevantes, según la tipología de competencias consensuada en el ámbito internacional (Eurydice, 2002). En general, las competencias clave hacen referencia a la educación básica, mientras que al hablar de las competencias genéricas y específicas suelen referirse a la enseñanza universitaria.

\begin{tabular}{|c|c|c|}
\hline \multicolumn{2}{|l|}{ competencia } & $\begin{array}{l}\text { "Una competencia es más que conocimientos y destrezas. Involucra la } \\
\text { habilidad de enfrentar demandas complejas, apoyándose en y } \\
\text { movilizando recursos psicosociales (incluyendo destrezas y actitudes) en } \\
\text { un contexto en particular (OCDE, 2005, 3) } \\
\text { "La capacidad de movilizar adecuadamente el conjunto de } \\
\text { conocimientos, capacidades, habilidades y actitudes necesarias para } \\
\text { realizar actividades diversas con un cierto nivel de calidad y eficacia" } \\
\text { (Bizquerra Alzina, R. y Pérez Escoda, N., 2007, 63) } \\
\text { "Capacidad de una persona para aplicar correctamente los resultados de } \\
\text { aprendizaje obtenidos a un contexto concreto (en la educación, el trabajo } \\
\text { o el desarrollo personal o profesional). La competencia no se limita a } \\
\text { elementos cognitivos (uso de teorías, conceptos o conocimientos tácitos); } \\
\text { abarca asimismo aspectos funcionales (capacidades técnicas), cualidades } \\
\text { interpersonales (p.e. capacidades sociales u organizativas) y valores } \\
\text { éticos" (CEDEFOP, 2008). }\end{array}$ \\
\hline $\begin{array}{l}\text { Enseñanza } \\
\text { básica }\end{array}$ & $\begin{array}{l}\text { Competencia } \\
\text { clave } \\
\text { (o básica) }\end{array}$ & $\begin{array}{l}\text { "Combinación de conocimientos, capacidades y actitudes adecuadas al } \\
\text { contexto (...) Son aquellas que todas las personas precisan para su } \\
\text { realización y desarrollo personales, así como para la ciudadanía activa, la }\end{array}$ \\
\hline
\end{tabular}

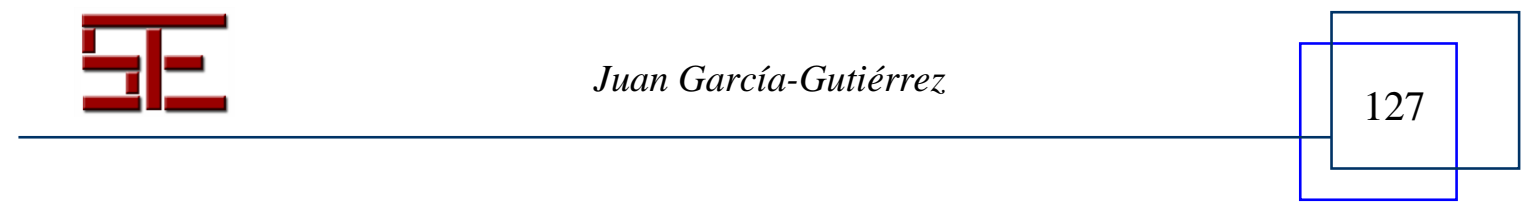




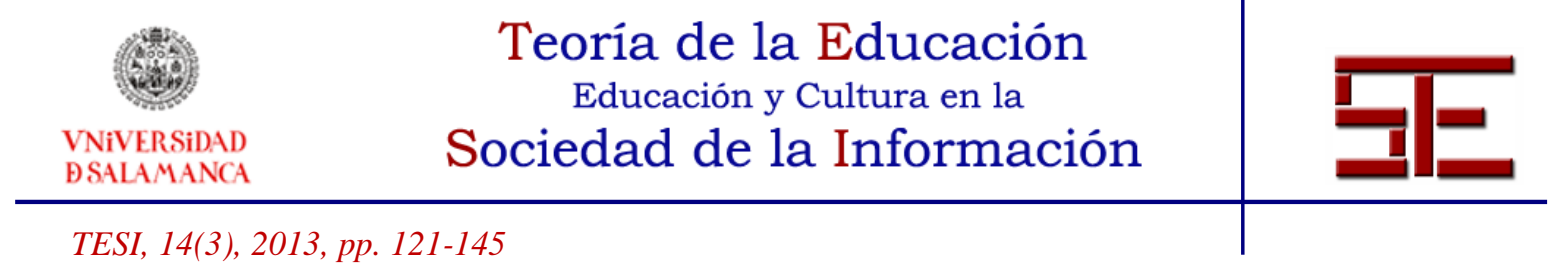

\begin{tabular}{|c|c|c|}
\hline & & inclusión social y el empleo" (DO L 394, de 18 de diciembre de 2006). \\
\hline \multirow{2}{*}{$\begin{array}{l}\text { Educación } \\
\text { Superior }\end{array}$} & $\begin{array}{l}\text { Competencia } \\
\text { genérica } \\
\text { (o } \\
\text { transversal) }\end{array}$ & $\begin{array}{l}\text { "Competencias independientes de las materias o transversales. No están } \\
\text { ligadas a ninguna disciplina sino que se pueden aplicar a una variedad de } \\
\text { áreas de materias y situaciones" (Eurydice, 2002,16). }\end{array}$ \\
\hline & $\begin{array}{l}\text { Competencia } \\
\text { específica }\end{array}$ & $\begin{array}{l}\text { "Se trata de competencias vinculadas al perfil profesional y que se } \\
\text { adquieren específicamente en determinadas titulaciones" }\end{array}$ \\
\hline
\end{tabular}

Cuadro 1. Principales definiciones y clasificación de las competencias en el ámbito educativo

Sin embargo la "educación por competencias" ha recibido importantes críticas. En general podemos encontrar dos tipos de argumentos. Uno que viene a insistir en el hecho de que no pueden enseñar competencias "desvinculadas" o independientemente de un campo de conocimiento específico (que vendría a coincidir con el currículum en las asignaturas o materias); por otro lado, otro de los argumentos viene a criticar el carácter reduccionista de este tipo de educación por considerar la educación desde un punto de vista meramente economicista reduciendo el proceso educativo a capacitación laboral (ITE, 2010). En el siguiente cuadro aparecen resumidos los aspectos positivos y negativos del enfoque de competencias.

-Explicitan y reconocen los saberes implícitos asociados al trabajo que hasta el momento eran ignorados;

-Ofrecen una alternativa a la selección de saberes escolares iniciales basados en las disciplinas y los títulos.

- Aportan a los formadores y a las organizaciones referentes de análisis comunes que hasta el momento no tenían.

-Proporcionan un puente útil entre la acción y los conocimientos definiendo cualificaciones a partir de comportamientos observables y medibles, claramente definidos y catalogados.

-Permiten, a primera vista, un avance social aplicando las reglas propias de una pedagogía humanista "centrada en el aprendiz" otorgándole más control y autonomía en su aprendizaje.
-La noción actual de competencia se inscribe en una visión analítica de racionalización y de normalización objetiva de comportamientos restringidos, que conduce a una fragmentación de unidades en detrimento de las dimensiones de integración y de globalidad de adaptación propias de las actividades.

-La explicitación objetiva de las actuaciones observables conduce a formulaciones muy abstractas que no consideran los fundamentos implícitos de los conocimientos en situación, de la interacción social y de las prácticas culturales que han sido puestos de manifiesto por las investigaciones etnográficas.

- La actividad competente se reduce a enumeraciones que suman cerradas y estáticas, minuciosas e interminables de roles, tareas y actos atomizados, cuya simple yuxtaposición es juzgada como suficiente para rendir cuentas ante la actividad;

-La evaluación de las competencias no contempla la finalidad formativa.

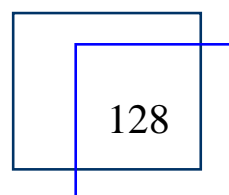




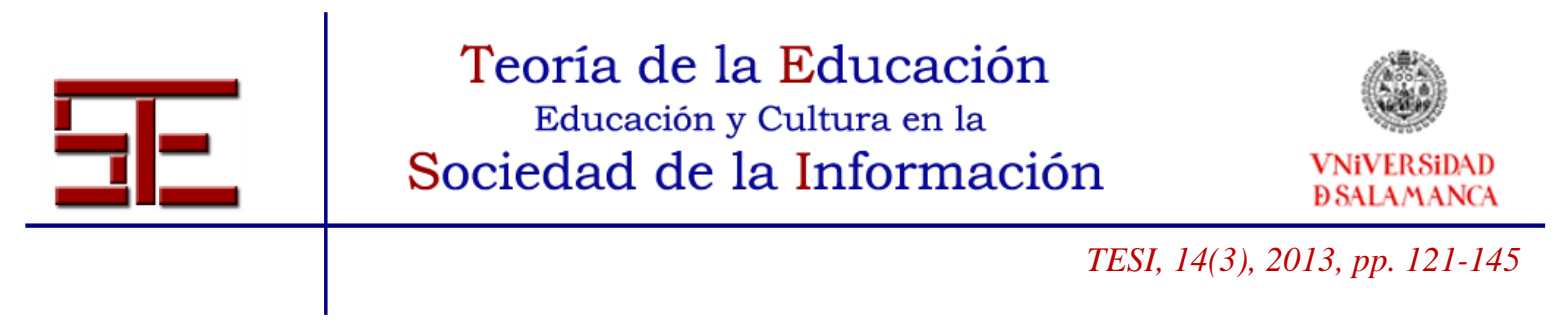

Cuadro 2. Aspectos positivos y negativos del enfoque de las competencias (cit. por Navío Gámez, 2005, 215)

Si nos centramos en las competencias como "acciones observables y efectivas", en el sentido que indican Asensio Aguilera et. al. (2012, 195):

\begin{abstract}
"la cosa se agrava aun mas cuando de lo que se habla es de desarrollar competencias de las que el docente no puede dar razón o de las que resulta harto problemático vislumbrar la eficiencia de las acciones supuestamente derivadas de la misma. Tal sería el caso, por ejemplo, de las “competencias éticas". Porque, ¿a qué nos referimos aquí por "acción eficiente”? ¿Cómo se evalúa esa "efectividad"?. Por lo que parece allá donde desaparece el criterio de "productividad" o cuanto no pueda ser directamente observable o cuantificable, diríamos que la idea de competencia se esfuma, lo que no siempre es tenido en cuenta".
\end{abstract}

Sin embargo, toda la arquitectura de la educación superior se basa, justamente, en la noción de competencia, por lo que se hace necesario, como señalan Alberici y Serreri $(2005,26)$,

"trascender su dimensión puramente funcionalista, ampliando su horizonte de estudio y de investigación (...) en el sentido de confluencia entre saberes, comportamientos, habilidades, entre conocer y hacer, que se realiza en la vida de los individuos, en el sentido de saber actuar en los distintos contextos de forma reflexiva y con sentido".

\title{
3. COMPETENCIAS ÉTICAS EN EL CIBERESPACIO: DELIMITACIÓN PEDAGÓGICA DEL “NIVEL DE USO” Y DEL "NIVEL DE SENTIDO”
}

\subsection{Competencias digitales v. Competencias éticas}

La tesis de partida en este apartado es la siguiente: moverse y orientarse en el ciberespacio no sólo implica el domino de ciertas competencias digitales (nivel de uso) sino que también supone la adquisición y desarrollo de competencias éticas (nivel de sentido). Y ello tanto en el ámbito personal como en el laboral. Sin duda los datos sobre el impacto de internet, software y uso de dispositivos (móviles, sobre todo) tanto en el ámbito laboral como personal contrasta con la escasa formación que las universidades y centros educativos en general ofrecen en esta dirección. Concretamente, podemos tomar como referencia los mapas de las titulaciones educativas, por ejemplo en los casos de pedagogía y Educación Social, no encontramos esta conexión entre ambas competencias. Por ejemplo, en el Libro blanco sobre el título de grado en Pedagogía y Educación Social (ANECA, 2013) aparecen incluidas dos tipos de competencias éticas. La formulación de éstas competencias aparece recogida en el siguiente cuadro.

\begin{tabular}{|l|l|l|}
\hline Competencia & Definición & Elementos \\
\hline $\begin{array}{l}\text { Compromiso } \\
\text { ético }\end{array}$ & $\begin{array}{l}\text { comportamiento } \\
\text { consecuente con los }\end{array}$ & $\begin{array}{l}\text { Conocimiento del código deontológico. Actúa con integridad y } \\
\text { rectitud ante cualquier situación, incluso en situaciones que }\end{array}$ \\
\hline
\end{tabular}

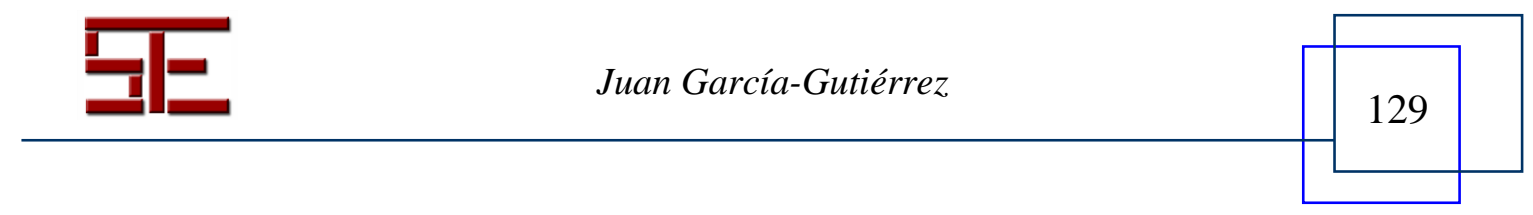




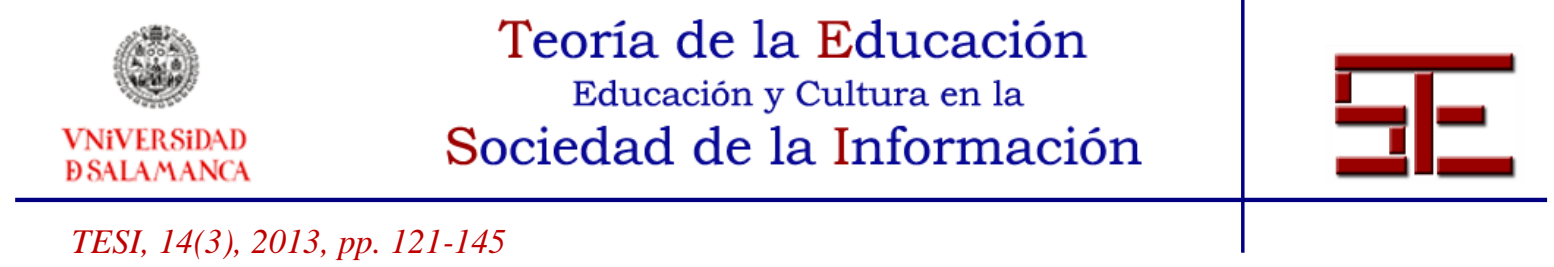

\begin{tabular}{|l|l|l|}
\hline & $\begin{array}{l}\text { valores personales y } \\
\text { el código } \\
\text { deontológico }\end{array}$ & $\begin{array}{l}\text { desfavorecen sus propios intereses. Honestidad tanto en } \\
\text { actividades académicas como en otros aspectos de la vida y no } \\
\text { ser pasivos ante la deshonestidad de otros. Asunción del código } \\
\text { deontológico. Ser respetuosos con las normas y leyes sin } \\
\text { necesidad de ser vigilados o controlados. Comportarse en } \\
\text { situaciones límite de manera íntegra y congruente con los } \\
\text { valores y creencias personales y profesionales. Aceptar y } \\
\text { reconocer los errores y responsabilizarse de las consecuencias. }\end{array}$ \\
\hline $\begin{array}{l}\text { Compromiso } \\
\text { con la } \\
\text { identidad, } \\
\text { desarrollo y } \\
\text { ética } \\
\text { profesional }\end{array}$ & $\begin{array}{l}\text { capacidad para } \\
\text { reconocerse y } \\
\text { valorarse } \\
\text { como profesional } \\
\text { servicio a la } \\
\text { comunidad y se } \\
\text { preocupa por su } \\
\text { actualización } \\
\text { permanente } \\
\text { respetando y } \\
\text { apoyándose en los } \\
\text { valores éticos y } \\
\text { profesionales }\end{array}$ & $\begin{array}{l}\text { actos relativos a la profesión, mostrar interés por actualizarse, } \\
\text { estar al día en el avance de los conocimientos y técnicas propias } \\
\text { se la profesión, mostrar abiertamente su postura ética ante } \\
\text { situaciones controvertidas }\end{array}$ \\
\hline
\end{tabular}

Cuadro 3. Competencias éticas en los títulos de grado en Pedagogía y Educación Social (ANECA, 2013)

Por su parte, en el Libro blanco sobre el título de grado en Pedagogía y Educación Social la competencia digital aparece expresada como competencia transversal de carácter instrumental, tal y como también se recoge en el cuadro siguiente.

\begin{tabular}{|l|l|l|}
\hline Competencia & Definición & Elementos \\
\hline & $\begin{array}{l}\text { capacidad para utilizar } \\
\text { las TIC como una herramienta } \\
\text { para la expresión y la }\end{array}$ & \\
comunicación, para el acceso a & $\begin{array}{l}\text { Manejo del ordenador a nivel de } \\
\text { usuario, conocimiento y uso de } \\
\text { medios audiovisuales, } \\
\text { Utilización de las TIC en el } \\
\text { ámbito de estudio y contexto } \\
\text { profesional }\end{array}$ & $\begin{array}{l}\text { multimedia, uso de Internet para } \\
\text { medio de archivo de datos y } \\
\text { documentos, para tareas de } \\
\text { presentación, para el } \\
\text { aprendizaje, la investigación y } \\
\text { cooperativamente }\end{array}$ \\
& el trabajo cooperativo. & \\
\hline
\end{tabular}

Cuadro 4. Competencia digital en los títulos de grado en Pedagogía y Educación Social (ANECA, 2013)

En el próximo cuadro aparecen recogidas también diversas formulaciones de la "competencia ética", tal y como se encuentra en los planes de estudio de algunas Universidades españolas. El cuadro no tiene tanto afán exhaustivo como analítico, en el sentido de mostrar de qué manera se entiende la citada competencia en los mapas de las titulaciones de Educación Social de las citadas Universidades.

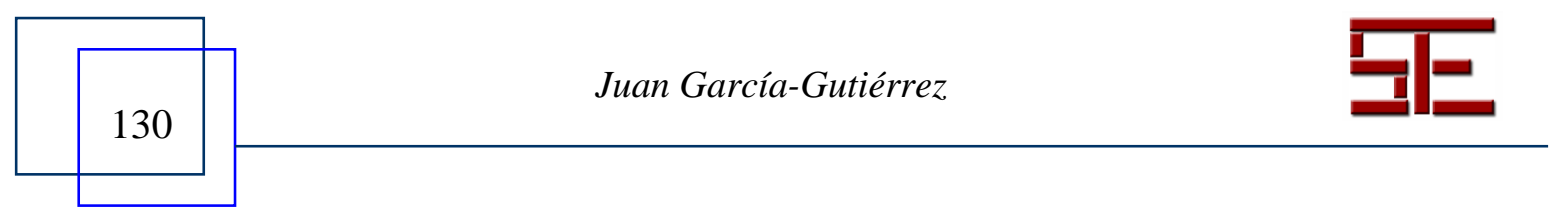




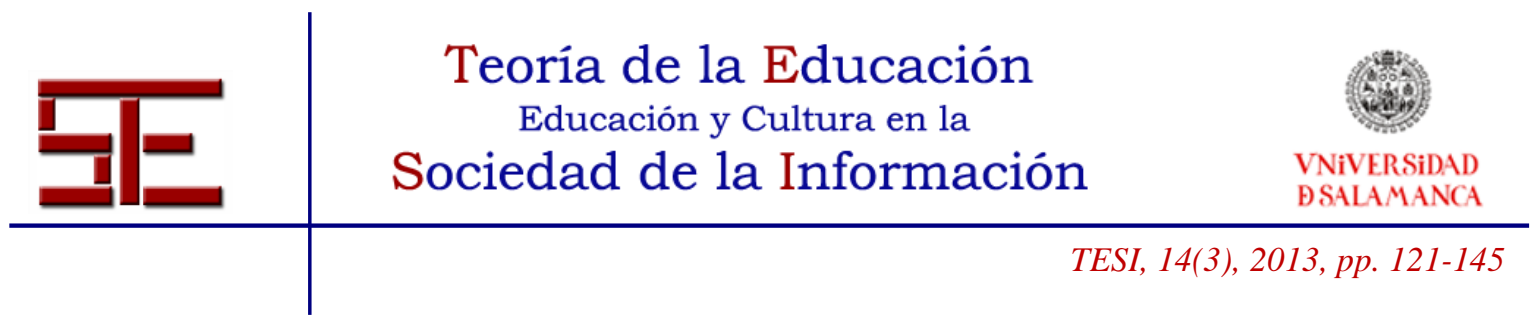

\begin{tabular}{|c|c|c|}
\hline $\begin{array}{l}\text { Tipo de } \\
\text { competencia }\end{array}$ & Definición, elementos & Universidad \\
\hline $\begin{array}{l}\text { Competencia } \\
\text { genéricas }\end{array}$ & $\begin{array}{l}\text { Aplicar los conocimientos, técnicas e instrumentos educativos y } \\
\text { las competencias adquiridas en su trabajo de forma profesional } \\
\text { y ética. }\end{array}$ & \multirow[b]{2}{*}{$\begin{array}{l}\text { Universidad } \\
\text { Autónoma de } \\
\text { Barcelona }\end{array}$} \\
\hline $\begin{array}{l}\text { Competencias } \\
\text { específicas }\end{array}$ & $\begin{array}{l}\text { Mantener una actitud de respeto hacia el medio (natural, social y } \\
\text { cultural) para fomentar los valores, comportamientos y prácticas } \\
\text { sostenibles que atiendan a la igualdad de género, a la equidad y } \\
\text { al respeto de los derechos humanos. }\end{array}$ & \\
\hline \multirow[t]{2}{*}{$\begin{array}{l}\text { Competencias } \\
\text { generales }\end{array}$} & $\begin{array}{l}\text { Compromiso ético activo con los derechos humanos, la igualdad } \\
\text { entre hombres y mujeres y la sostenibilidad }\end{array}$ & \multirow[t]{2}{*}{$\begin{array}{l}\text { Universidad de } \\
\text { Valencia }\end{array}$} \\
\hline & Compromiso con la identidad, desarrollo y ética profesional. & \\
\hline $\begin{array}{l}\text { Competencia } \\
\text { transversal }\end{array}$ & $\begin{array}{l}\text { Que los estudiantes desarrollen la intervención socioeducativa } \\
\text { desde claves éticas y de respeto a la deontología de la profesión. }\end{array}$ & $\begin{array}{l}\text { Universidad del } \\
\text { País Vasco }\end{array}$ \\
\hline $\begin{array}{l}\text { Competencias } \\
\text { generales } \\
\text { (sistémicas) }\end{array}$ & Compromiso con la identidad, desarrollo y ética profesional. & \multirow[b]{2}{*}{$\begin{array}{l}\text { Universidad de } \\
\text { Salamanca }\end{array}$} \\
\hline Objetivo & $\begin{array}{l}\text { Objetivo 6: Conocer y actuar conforme a los principios } \\
\text { deontológicos del educador social. } \\
\text { E30. Desarrollar una actitud empática, respetuosa, solidaria y de } \\
\text { confianza hacia las personas e instituciones objeto de la } \\
\text { intervención socioeducativa. }\end{array}$ & \\
\hline
\end{tabular}

Cuadro 5. La formulación de la competencia ética en los planes de estudio de Educación Social.

En general, se ha definido la "competencia ética" como,

\begin{abstract}
“aquellas capacidades que la persona experimenta en situaciones reales donde se plantea un conflicto moral, para deliberar de forma justificada y actuar coherentemente, reconociendo en cada caso la globalidad de la situación y a todos los involucrados, a la vez que respetando la dignidad, la integridad y la individualidad de cada uno. El uso de dichas competencias implica un análisis de la propia conducta, el interrogarse sobre las decisiones y actuaciones anteriores y trabajar sobre la propia persona, mediante la confrontación regular entre el origen y el sentido de las decisiones o actuaciones y los valores implícitos. De ahí que la competencia ética no es un resultado acabado, sino un proceso, en el cual la autoevaluaciones el único procedimiento posible y coherente" (Burguet Arfelis y Buxarrais Estrada, 2012, 222).
\end{abstract}

Por su parte, los profesores A. Villa Sánchez y M. Poblete Ruiz $(2008,226)$ en su trabajo sobre aprendizaje por competencias, también describen y profundizan en la

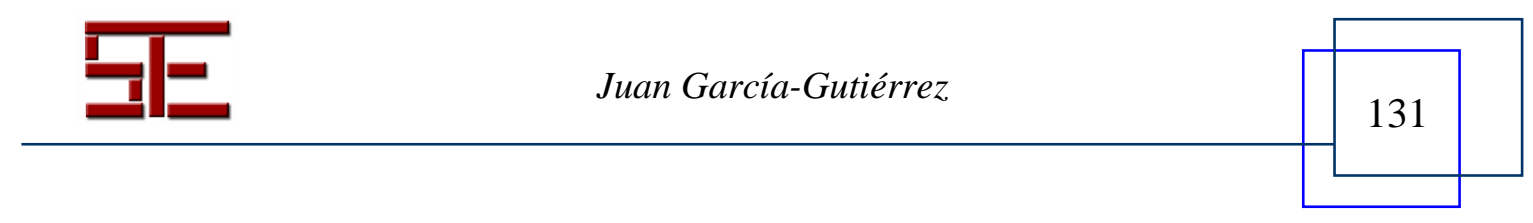




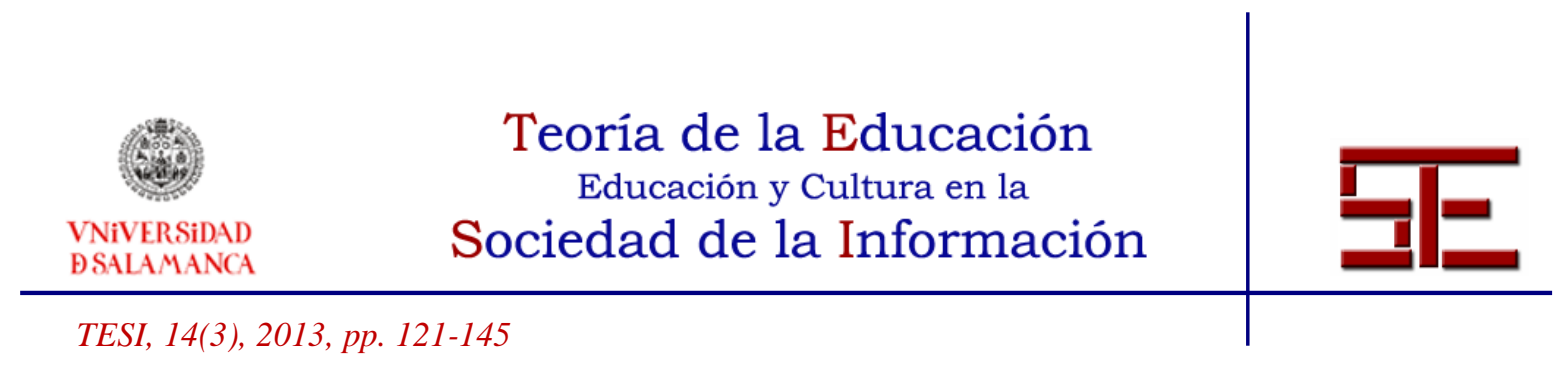

competencia "sentido ético" clasificándola como una "competencia genérica interpersonal" que consiste en "la inclinación positiva hacia el bien moral de uno mismo y de los demás (esto es, hacia todo aquello que es bueno o tiende a la integridad o realización del individuo) y la constancia en el bien moral"; aunque su domino también lo relacionan con el pensamiento analítico, el pensamiento sistémico, el pensamiento crítico, al resolución de problemas, la toma de decisiones, la comunicación interpersonal, la diversidad y la interculturalidad, la adaptabilidad, la responsabilidad, la autonomía, la justicia, o la cooperación, etc.

A este punto nos encontramos con que la competencia ética aparece desvinculada del ciberespacio y lo mismo sucede con la competencia digital en relación a la ética (no existen referencias directas entre los ámbitos). Sin embargo, las relaciones entre educación, ética y ciberespacio las encontramos en tres direcciones (aunque por falta de espacio no las desarrollaremos en este trabajo). En efecto, a nuestro juicio, las implicaciones éticas del ciberespacio, desde una perspectiva pedagógica, abarcan tres ámbitos de reflexión:

1.Atendiendo a la creación y elaboración de dispositivos y software;

2.Atendiendo a la creación de contenidos y difusión de la información;

3.Atendiendo al impacto de lo anterior en el desarrollo del sujeto y las comunidades; Tanto la creación de dispositivos como la elaboración de software incidirá en el tipo de experiencia que el usuario tendrá con la tecnología. ${ }^{33}$ Igualmente la creación de contenidos y difusión de la información en una economía basada en el conocimiento tiene una importancia trascendental. Tanto el primer como el segundo punto indicen directa o indirectamente en el desarrollo de las personas y de los pueblos, hasta tal punto que para muchos el acceso a las tecnologías computacionales constituye ya un derecho humano. ${ }^{34}$ A continuación, vamos explorar el último de los ámbitos propuestos (aunque todos guardan íntima relación).

\subsection{Delimitación pedagógica de los niveles de uso y sentido}

Pedagógicamente, docentes y educandos interactúan y se apropian de las tecnologías de maneras diversas. Algunos basan esta apropiación sólo en el "uso"; mientras que para otros también es importante el "sentido". Unos sólo muestran un interés pragmático por los usos y aplicaciones de la tecnología, alejándose de otras consideraciones; otros se muestran también preocupados por el sentido. Efectivamente, el sentido presupone el uso, pero no necesariamente ocurre lo mismo al contrario. Veamos brevemente qué podemos entender por "nivel de uso" y qué entendemos por "nivel del sentido", y porqué establecer niveles.

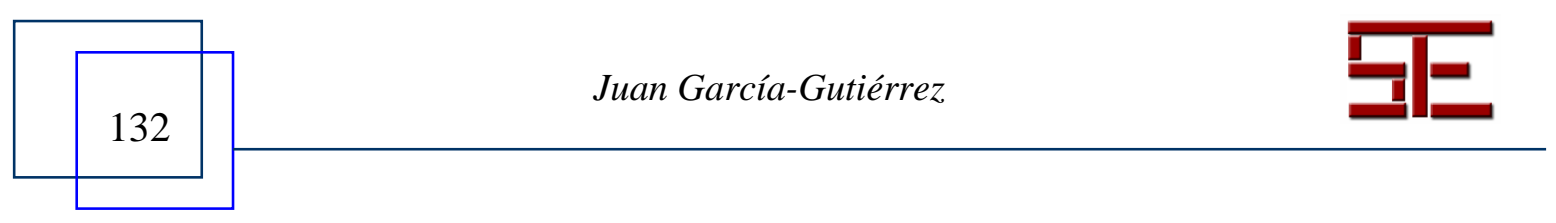




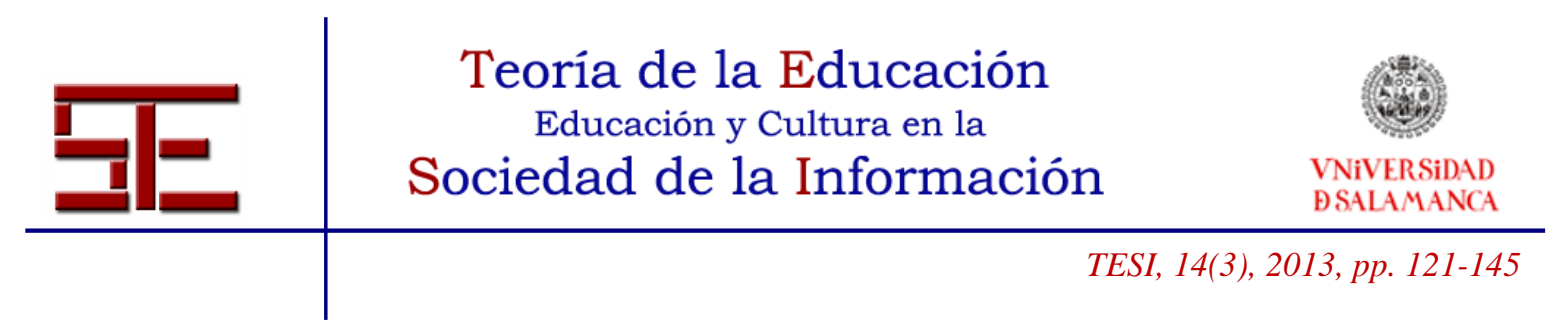

El nivel de uso se caracteriza justamente por el predominio de una "lógica del uso" o una "racionalidad utilitaria"; esto es, una visión instrumental de la tecnología, considerada también de forma neutral (ya que la valoración moral dependerá del "uso" que se haga de ella). Podemos entender la lógica del uso como una evolución progresiva de la racionalidad instrumental a la racionalidad tecnológica. Algo que ya criticaba la escuela de Frankfurt y que se caracteriza por una hegemonía del conocimiento científico, al modo positivista, y por una inversión de la relación entre fines y medios. Así, la racionalidad tecnológica se apropia de esta inversión postergando los fines a un papel secundario. En este horizonte, señala Bustamante Donas (2001) aparece una sociedad cuyos fines son definidos por los medios (competencia, optimización, controlabilidad), y el instrumento se convierte en un fin en sí mismo. En este sentido, continua su crítica, señalando como:

\begin{abstract}
"la crítica de la razón instrumental de Marcuse y Horkheimer denunció en su momento los mecanismos de dominación que operan en la tecnología moderna, que se extiende hasta la pérdida de la independencia del pensamiento moral con respecto al pensamiento científico. (...) ciencia y tecnología se han transformado en formas específicas de control y dominación, trabajando no ya en la consecución de una transformación del hombre o de la historia, sino en aras de un proyecto específico: el control técnico de la naturaleza. Si la tecnología ofrecía hasta ahora un mayor control del hombre sobre su vida cotidiana, al mismo tiempo impedía que el hombre se encontrara asimismo más allá de la alienación de un mundo artificializado" (Bustamante Donas, 2001, 10).
\end{abstract}

Para muchos la finalidad educativa estriba en promover y universalizar el uso de la tecnología y dispositivos, así como su introducción en ambientes escolares. En este nivel, el tratamiento educativo de la tecnología tiene que ver con la adquisición de competencias digitales entendidas como herramientas que facilitan el uso de los productos tecnológicos (software, internet y dispositivos). En esta lógica, el objetivo pedagógico terminaría con la adquisición de habilidades y competencias necesarias para el manejo del aparato. Este nivel sería el más cercano a los llamados "inmigrantes digitales" ya que habiendo nacido en un entorno "no digital" necesitan adquirir herramientas, habilidades y competencias necesarias para moverse y controlar un mundo distinto al que ellos conocían y en el que se habían formado.

Sin embargo, también es importante preguntarse y reflexionar críticamente por el sentido que tiene la tecnología. Es aquí donde se abre paso la ética y la filosofía de la educación como ámbitos destinados a cuestionar y reflexionar sobre el sentido pedagógico de la tecnología. Pero se introduce una particularidad. En esta reflexión que se propone los tiempos no son los mismos. El tiempo del "uso" es un tiempo inmediato, la rapidez del instante tecnológico contrasta con el tiempo necesario para pensar y elaborar un discurso acerca del sentido de la tecnología. Sin lugar a dudas, las tecnologías "están-ahí" y resulta estéril, a estas alturas, el debate entre tecnófilos o tecnofóbicos ya que lo verdaderamente relevante es el sentido y los espacios (escuela,

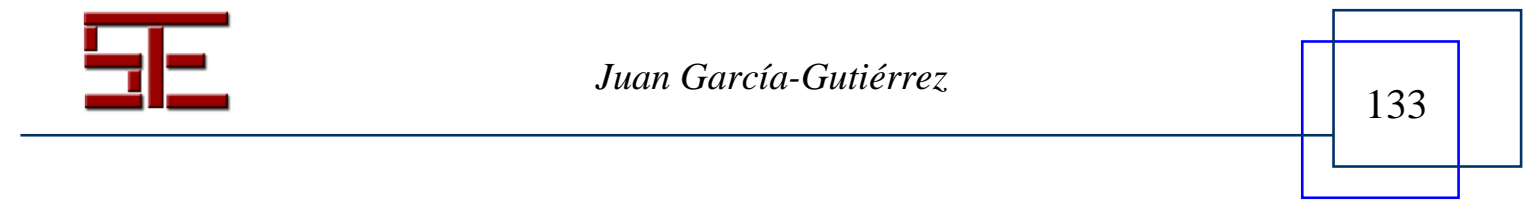




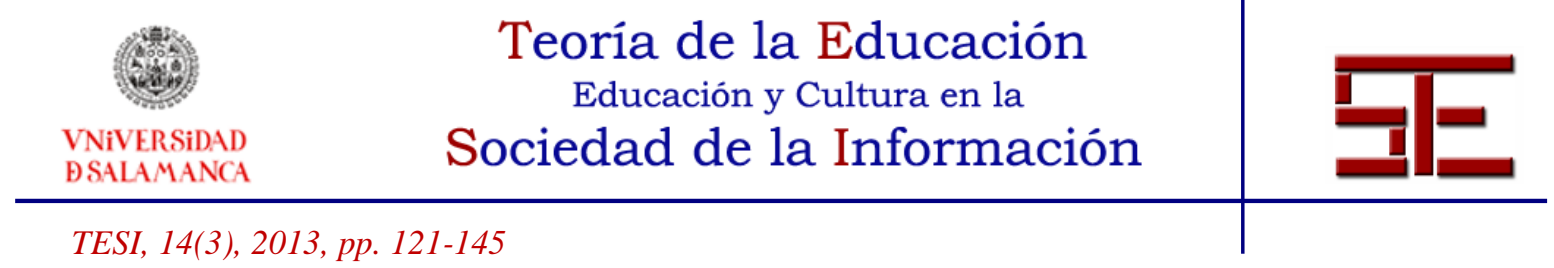

familia, personales, etc.) que educativamente concedemos a la tecnologías; qué valores nos permiten promover y qué tipo de relación educativa nos condicionan, ya que la tecnología, en ningún caso, nos ahorra el esfuerzo pedagógico de tener que reflexionar sobre el sentido de la acción educativa (García Gutiérrez, 2012).

Junto al nivel de uso se sitúa el nivel de sentido, caracterizado por una "racionalidad práctica" (no instrumental), una "lógica del sentido", que tiene que llevar a educadores y educandos, y en general a todos aquellos "usuarios" de la tecnología, a reflexionar sobre la despersonalización a la que puede conducir una mera "lógica del uso". En la crítica apuntada por el Círculo de Frankfurt, la técnica anula incluso a la propia ética e impide que el sujeto humano se pregunte por su propia identidad o por la escala que ha de medir el mundo vivido (Pérez Herrans, 2008). Ya pensemos en la necesidad de un enfoque transversal entre competencias ético-digitales, como el propuesto por las profesoras Burguet Arfelis y Buxarrais Estrada (2012); ya sea un enfoque en el que se identifican diferentes niveles de apropiación de la tecnología, es necesaria una reflexión constante sobre el sentido que para cada uno tiene la tecnología. No podemos perder de vista la "escala humana" a la que deberían estar sometidas también las tecnologías computacionales e informacionales.

Así, lo importante de la "lógica del sentido" es que nos permite distinguir entre objetos y sujetos, entre dispositivos, programas y personas, entre medios y fines educativos. Nos ayuda a comprender que las personas tienen valor en sí mismas y merecen respeto allá donde habiten (espacios físicos o virtuales). Nos ayuda a promover e identificar horizontes de plenitud humana a través de la tecnología, promoviendo los usos más positivos y reflexionando sobre aquellos negativos. A reflexionar críticamente desde una perspectiva humanista sobre los valores que promueven las tecnologías. No pasando por alto que las tecnologías están instrumentalmente vinculadas a al proceso educativo. Que como muy bien supo distinguir Jaspers hay distintos niveles de comunicación y que el proceso educativo no es sólo un proceso comunicativo optimizable tecnológicamente. La lógica del sentido ayuda al educador a plantearse este tipo de cuestiones y no pensar, por ejemplo, en el proceso educativo como un mero proceso de comunicación optimizable tecnológicamente. En este sentido, el educador debería estar en condiciones de ser capaz de pensar en qué medida mejora o se dificulta una relación educativa mediada por la tecnología.

\section{4. ¿QUÉ PIENSAN LOS PROFESORES DEL "NIVEL DE USO" Y DEL "NIVEL DE SENTIDO"?}

Los niveles de uso y sentido dibujan un continuo de ida y vuelta entre competencias digitales y éticas en la creencia de que el sentido crítico, la reflexión o el tacto pedagógico no se limitan al mundo educativo "físico" sino que también abarcan y

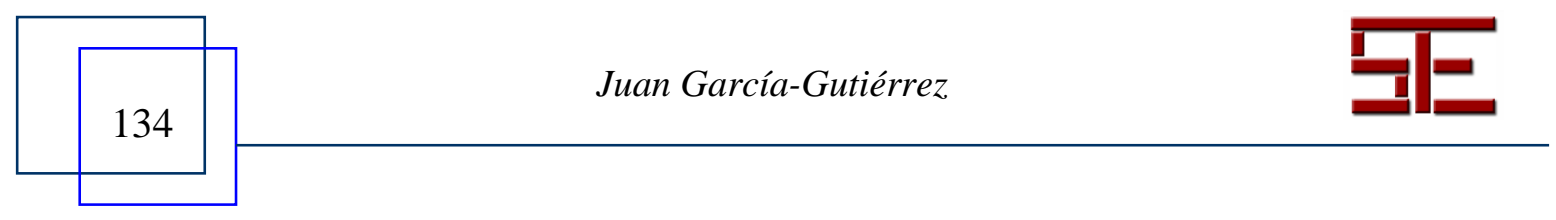




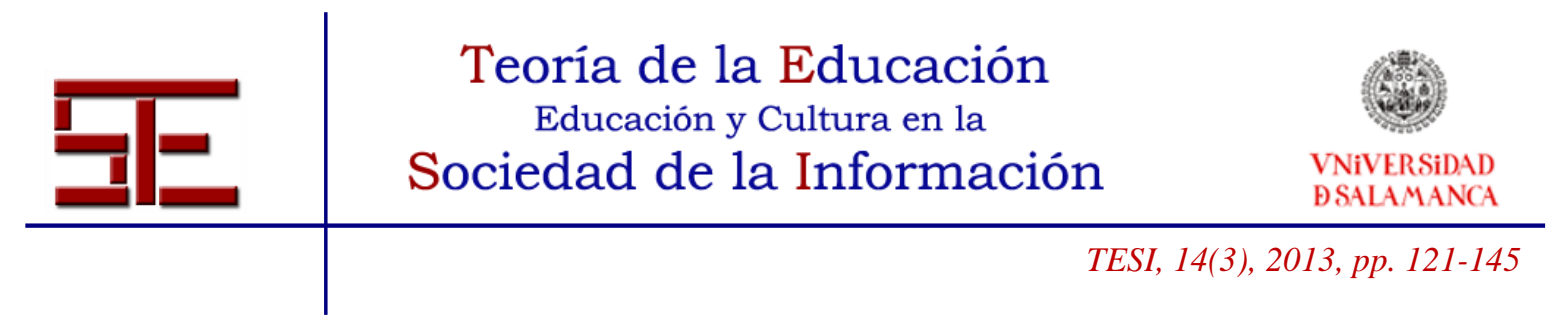

deberían estar presentes en el ciberespacio. En este punto, y a modo de ejemplo, se presentan brevemente parte los resultados del estudio exploratorio "Ciberespacio y educación: nivel de uso y nivel de sentido", realizado entre profesores de Educación Segundaria Obligatoria mediante grupos de discusión durante el curso 2012/13. ${ }^{35}$

El objetivo de este estudio era precisamente aproximarnos a cómo los profesores entienden y desarrollan la competencia digital; sus expectativas y formas de apropiación de la tecnología. Para ello, hemos considerado, como hipótesis de partida, dos niveles de apropiación de la tecnología por parte de los docentes: el nivel de uso y el nivel de sentido. En el primer nivel predomina una visión instrumental de la tecnología; orientada al acceso y a promover y universalizar su uso e introducción en el aula. En el nivel de sentido predomina la lógica de la comprensión, la reflexión, y la responsabilidad en la transmisión de valores en contextos educativos híbridos.

Dado el objeto de nuesta investigación, la metodología que hemos seguido es de carácter cualitativo. En nuestro caso hemos tratado de acercarnos al objeto de estudio teniendo presente investigaciones precedentes y trabajos teóricos sobre competencias digitales. ${ }^{36}$ Para el desarrollo de la investigación hemos recurrido a la técnica del grupo de discusión, con un posterior análisis cualitativo de datos asistido por ordenador (Computer Assisted Qualitative Data Analysis, CAQDA) mediante el uso del programa ATLAS.ti (free trial version 7).

La técnica de grupos de discusión permite estudiar y hacer emerger en un ambiente de confianza: los discursos, las relaciones complejas del sujeto con el tema estudiado que pueden escapar a preguntas concretas; discursos ideológicos e inquietudes; creencias que pueden estar detrás de lo explícito, etc. La composición de la muestra en nuestra investigación ha sido libre y heterogénera (en total 7 grupos de entre 4 y 7 profesores, de diversas Comunidades Autónomas); en los grupos de discusión han participado profesores de Asignaturas distintas, en centros públicos como privados, todos en el nivel de Educación Secundaria Obligatoria.

La discusión en los grupos ha sido orientada por cuestiones de tipo: ¿qué retos presentan a la educación tanto la introducción de las TICs como el uso que los estudiantes hacen en su tiempo de ocio?; ¿qué usos de internet aplicas en el aula?, ¿mueves a la reflexión ética sobre las nuevas dificultades?; ¿conoces o utilizas códigos éticos en el ámbito de internet?; ¿crees que puede el profesorado ayudar al alumno a desenvolverse en el ciberespacio?; ¿piensas que es positivo que alumnos y profesores compartan y se relacionan a través de redes sociales?; ¿se ha detectado algún caso de ciberbullying?; ¿se permite a los estudiantes que estén en clase con su ordenador y/o teléfono móvil?. A continuación presentaremos, en diferentes figuras, algunos de los resultados del estudio.

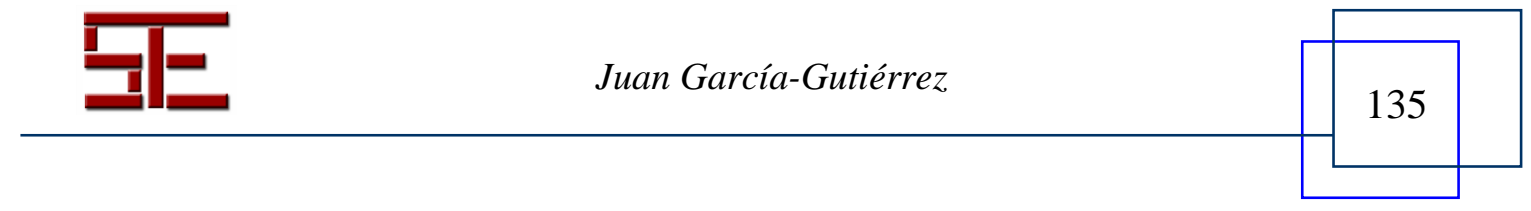




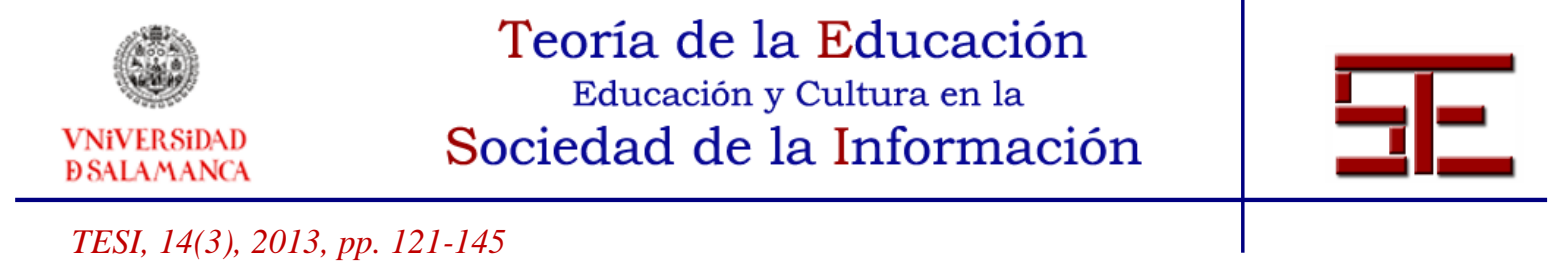

En primer lugar, el "word cruncher" (computo de palabras) nos ofrece una aproximación al tipo de discurso que predomina en los docentes en relación con las tecnologías, y sus principales intereses expresados en la frecuencia con que determinadas palabras aparecen repetidas en las fuentes primarias (transcripciones de los grupos de discusión). El recuento total asciende a 12.648. Una vez eliminados aquellos términos irrelevantes (artículos, signos de puntuación, etc.) los términos más repetidos en las transcripciones de los grupos de discusión han sido las siguientes:

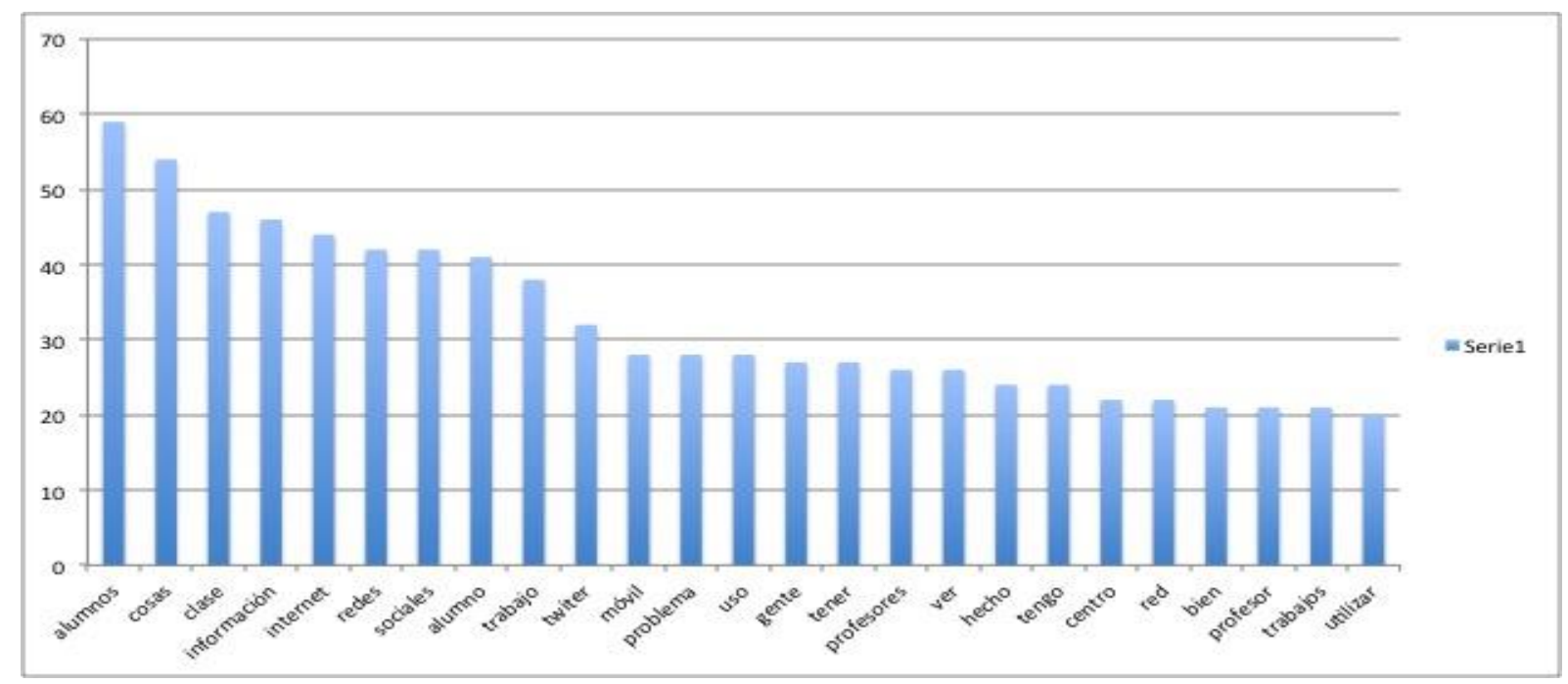

Cuadro 6. Listado de términos más repetidos en las fuentes primarias.

El análisis de las frecuencias pone de manifiesto algunas cuestiones interesantes. En primer lugar, la orientación al alumno. Al pensar en "tecnología" los docentes se refieren más a los alumnos que a ellos mismos (alumnos y alumno suman una frecuencia de 100 repeticiones). Un segundo hecho relevante es la importancia dada a internet (44 repeticiones) y a las redes sociales (aunque aparecen contabilizadas por separado "redes" y "sociales") como twitter (32 repeticiones) frente a otros recursos o software. También es significativa la cercanía en repeticiones entre los términos: "problema", "uso" y "móvil". En este sentido, la frecuencia de repetición del término "móvil" refleja la importancia (muchas veces problemática) de este tipo tipo de dispositivos tiene en los centros (máxime si también sumamos las repeticiones en los que aparece como "teléfono"). La presencia del término "uso" (junto a otros como "tener" o "hacer") refuerzan la hipótesis inicial sobre la extensión del "nivel de uso" en detrimento del "nivel de sentido" en el ámbito de la competencia digital.

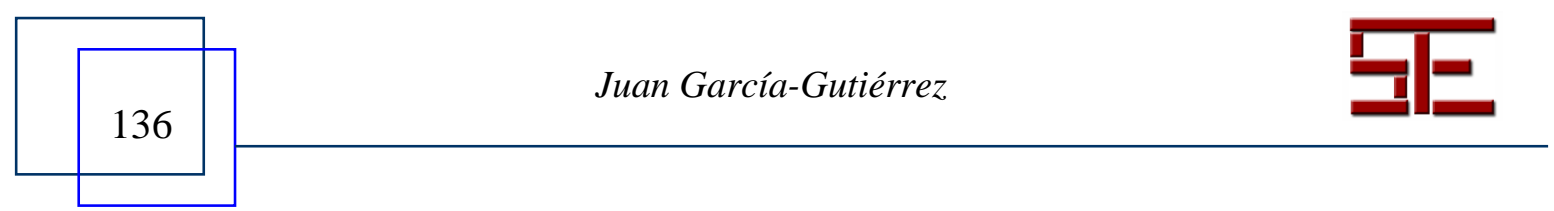




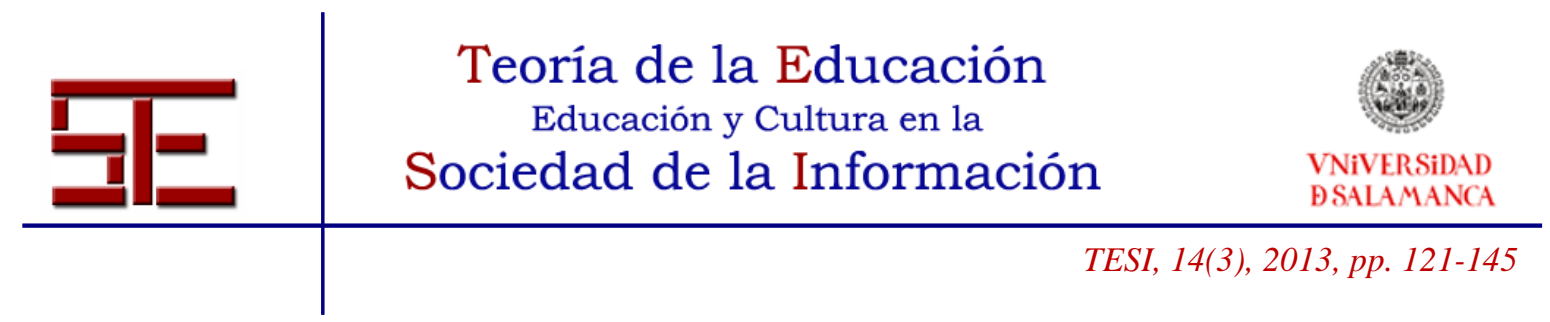

Por otra parte, contrasta que no aparezca más reiteración en algunos términos que expresan o tienen que ver más directamente con el ámbito digital, el ciberespacio o los contenidos multimedia. En el siguiente listado recogemos algunos términos con una repetición que oscila entre las 14 y las 3 repeticiones (el caso de "competencia digital" o "programas", respectivamente).

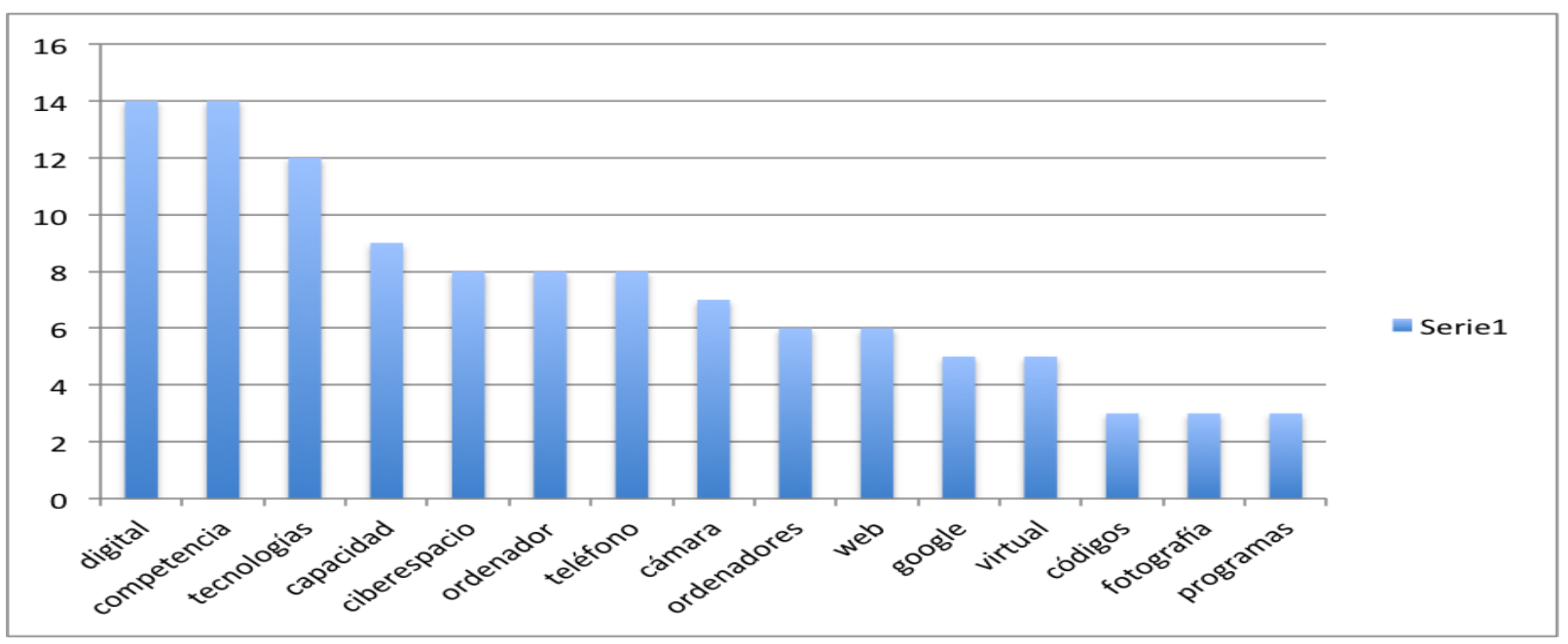

Cuadro 7. Listado de términos vinculados con el ciberespacio en las fuentes primarias.

Igualmente, también podemos preguntarnos ¿qué palabras se echan en falta? En efecto, términos como "reflexión", "autonomía", "crítico" (criticada, criterio, críticas), aparecen sólo una vez nombrados; "autoridad" 2 veces; y otros como "ética" (ético, éticos) o "control" cuentan con una frecuencia de repetición también baja, entre 8 y 6 repeticiones respectivamente.

Por otra parte, si tratamos de analizar los que entienden los profesores por "nivel de uso" y "nivel de sentido" podemos establecer una vinculación entre competencias digitales (en cuanto al nivel de uso) y competencias éticas (nivel de sentido). Principalmente entienden que el uso tiene que ver con "enseñar a utilizar las vías de información que el alumno tiene en la mano"; "buscar información y las mejores maneras de acceder e interpretar"; "que todo puede ponerse en todos sitios"; "que no por salir en google tiene que ser cierto". En el nivel de uso se tienen en cuenta destrezas que apuntan sobre todo a la comunicación y a los intercambios de información, según se refleja en la figura siguiente.

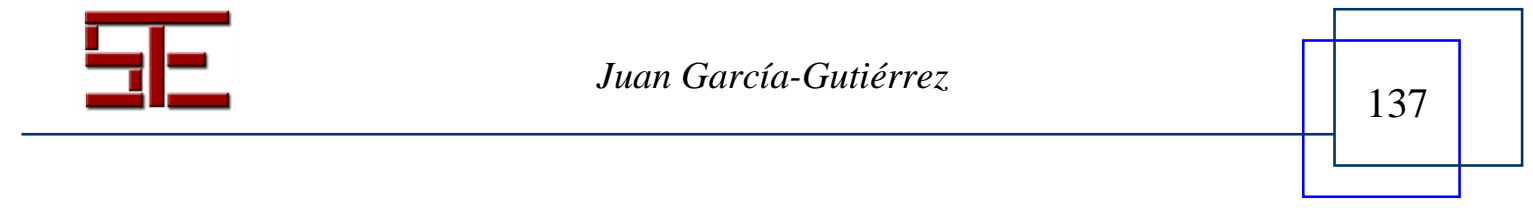




Teoria de la Educación
Educación y Cultura en la
$\begin{gathered}\text { VNiVERSIDAD } \\ \text { BSALAMANCA }\end{gathered}$

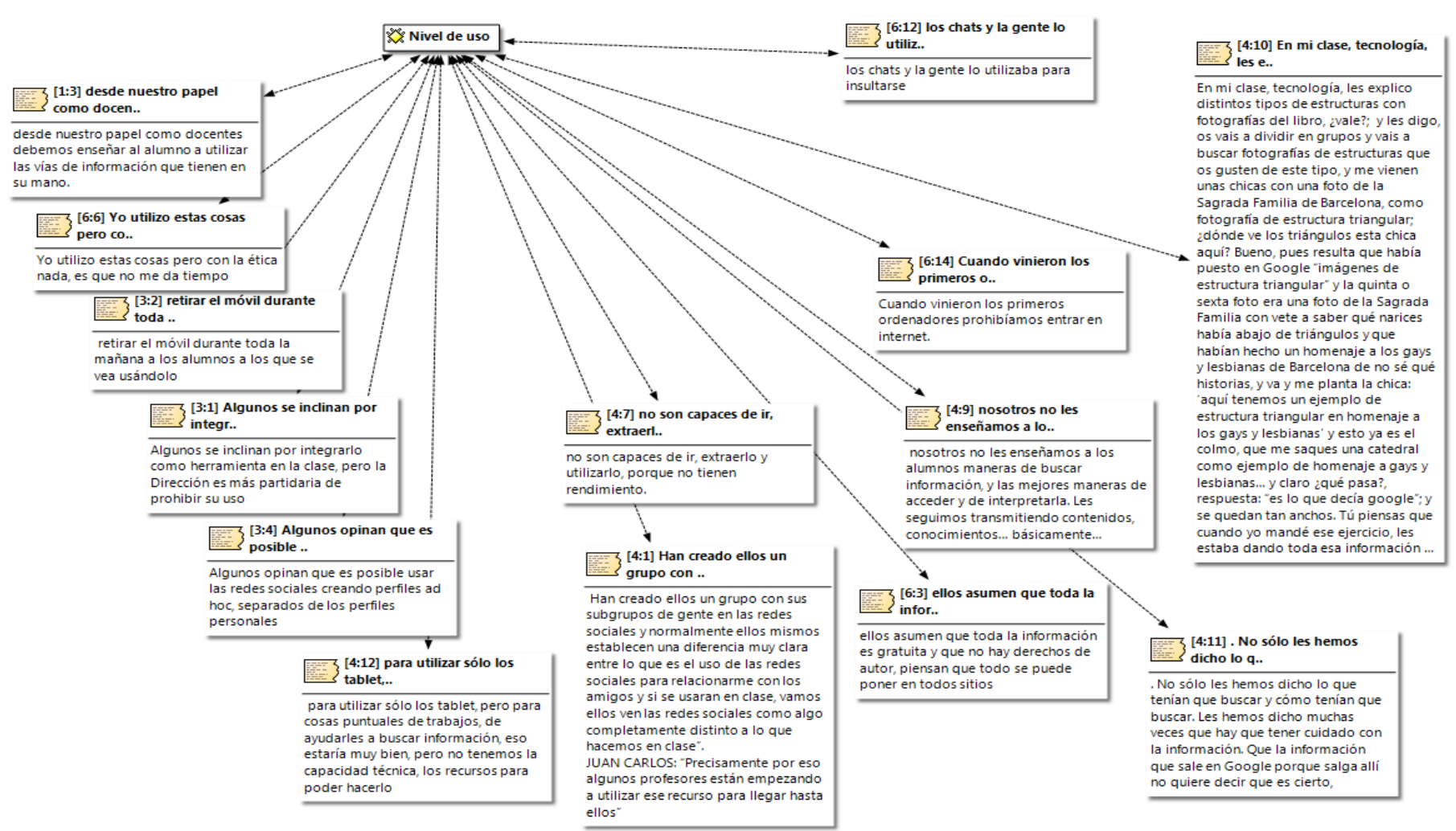

Figura 1. Aproximación a la noción "nivel de uso" desde el dircurso del profesorado

El nivel de sentido aparece vinculado a la dimensión ética del ciberespacio. Además, en este nivel se han detectado problemáticas que dirigidas a los alumnos, también inciden de forma especial en los propios docentes. Estas problemáticas, en ocasiones pueden estar detrás de las resistencias que se experimentan ante el uso o la introducción de tecnologías de la información y la comunicación en las clases. En efecto, se ha detectado como problemático para los docentes la dificultad para diferenciar entre espacios y tiempos formativos y espacios y tiempos para el ocio. Algo que también afecta a su propia privacidad y a la percepción que tienen de los espacios y los tiempos cuando median tecnologías de la información y la comunicación. La tecnología diluye la frontera entre tiempo de ocio y tiempo formativo o de trabajo; entre el aula y lo extraescolar. También es interesante el empleo de términos como control, protección que evidencian hasta que punto ha calado en el ámbito educativo el paradigma de la seguridad en detrimento de un enfoque desde la autonomía y la responsabilidad.

Para los docentes el nivel de sentido tiene que ver sobre todo con la relación con los otros. Si en el nivel de uso la mayoría de los comentarios apunta a la relación de los alumnos con la información y el conocimiento, en el nivel de sentido los docentes

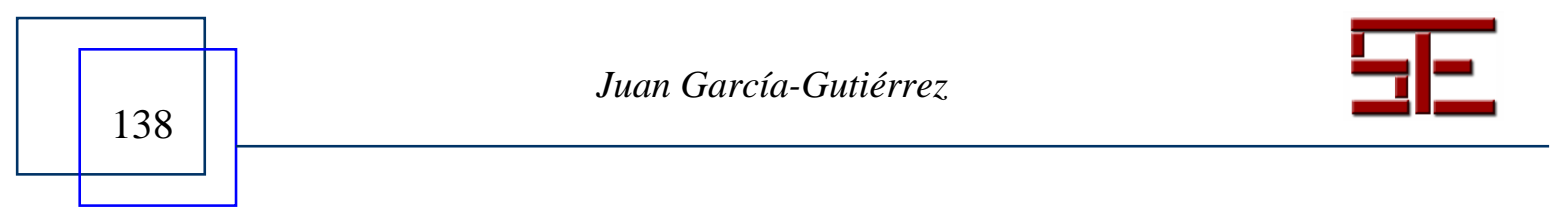




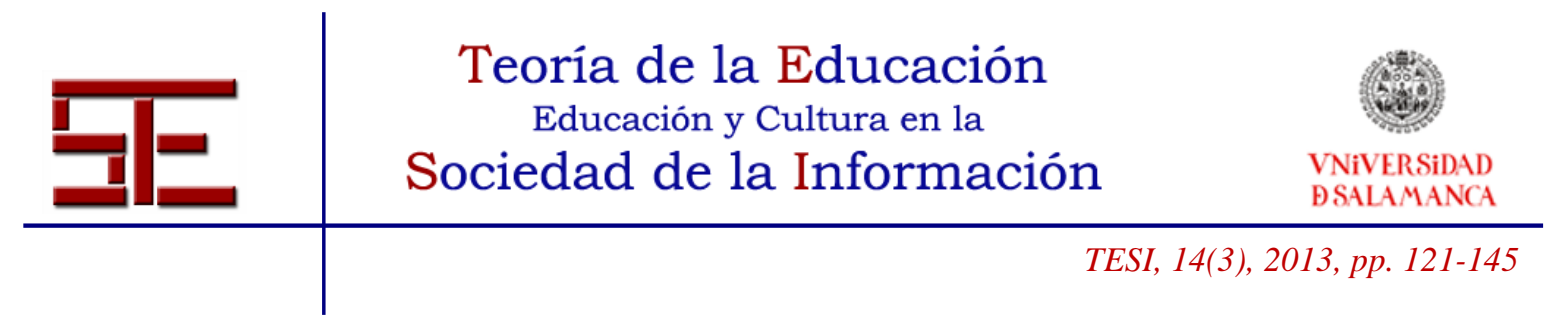

muestran preocupación por las relaciones: "algunos opinan que es posible usar las redes sociales creando perfiles ad hoc"; "derecho al olvido, que en la red no existe"; "distinguir la información correcta y la que no lo es"; "hay que educarlos en protegerlos"

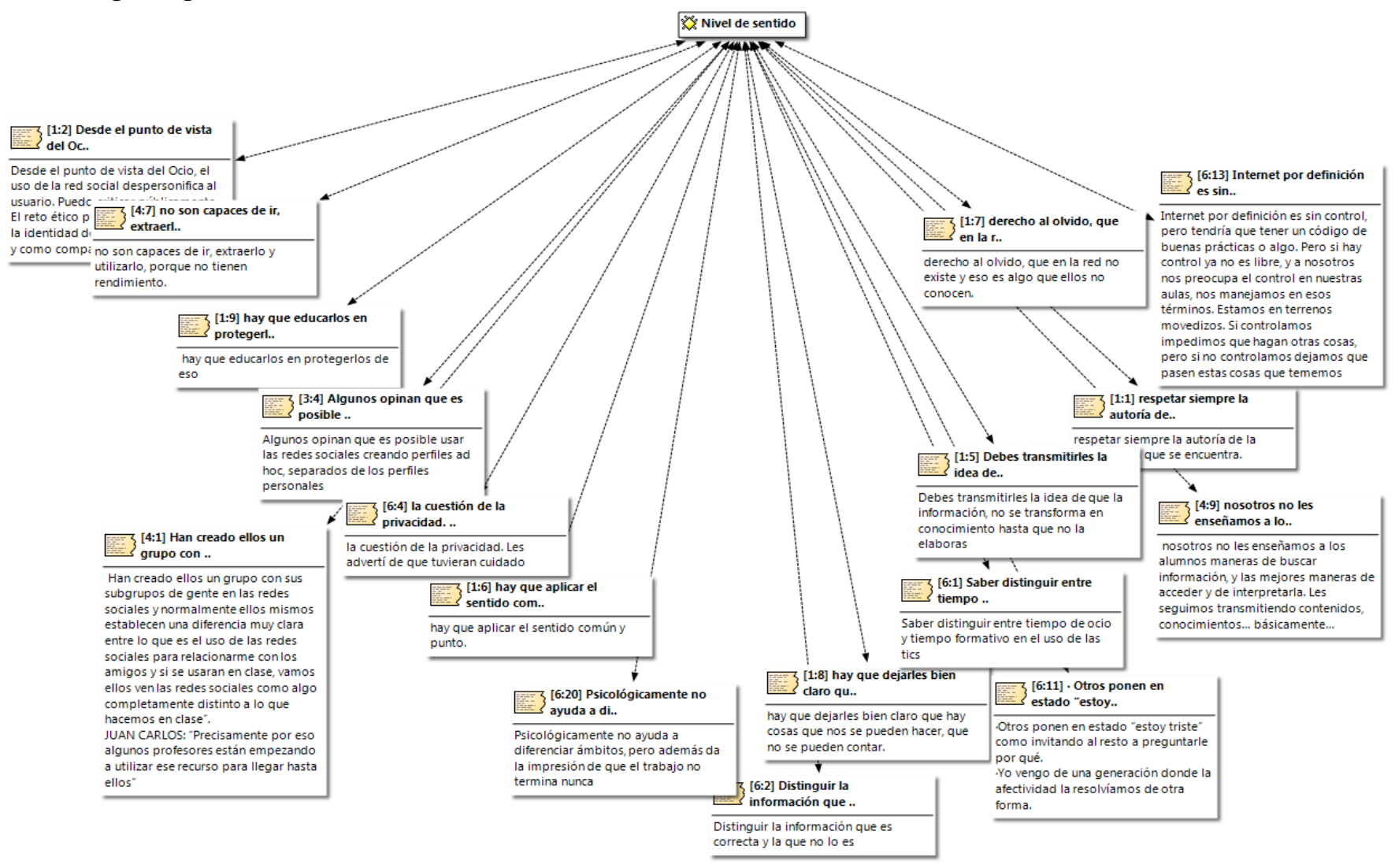

Figura 2. Aproximación a la noción "nivel de sentido" desde el dircurso del profesorado

\section{UN MUNDO TECNIFICADO NECESITA DE UNA FORMACIÓN HUMANÍSTICA}

A lo largo de éste trabajo se ha puesto de manifiesto la importancia que en el terreno educativo ha adquirido tanto el ciberespacio como el discurso sobre competencias. De tal modo que hemos tratado de analizar las competencias éticas y las competencias digitales poniendo de manifiesto su necesaria relación e interdependencia. Hemos mostrado como el discurso educativo sobre el ciberespacio no sólo se mueve en el "nivel de uso" sino que también es posible identificar un "nivel de sentido", en el que la racionalidad no es puramente instrumental sino que también es necesario contar con la

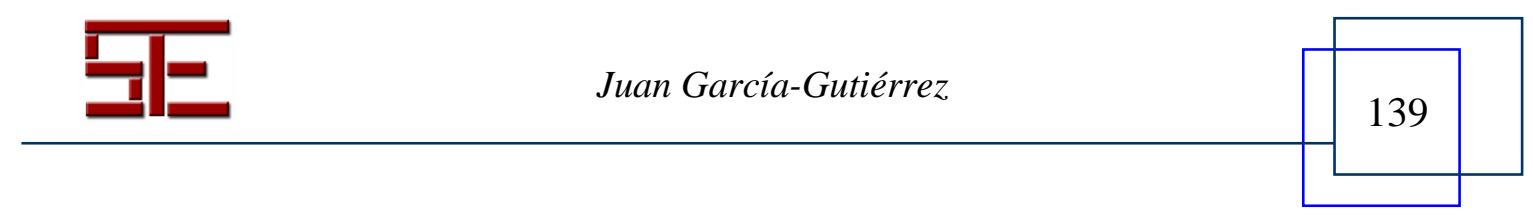




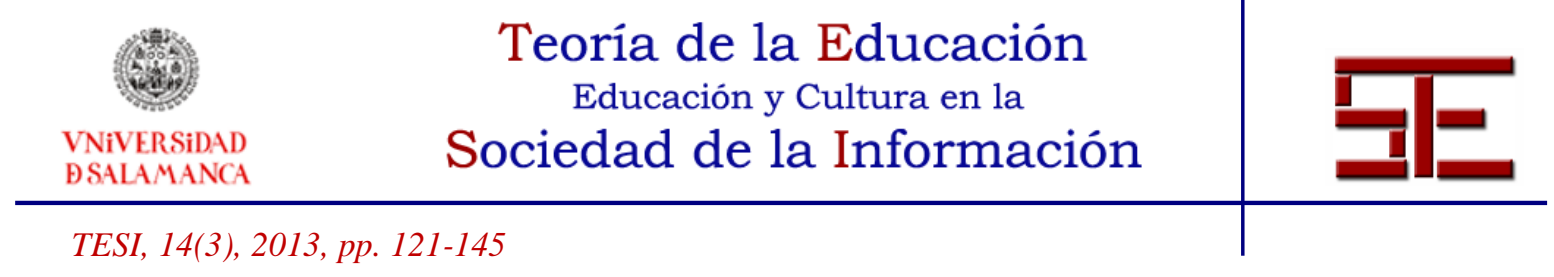

reflexión, el pensamiento crítico, y con la capacidad para ponerse en el lugar del otro. Todas ellas categorías invisibles a la razón instrumental.

Sin duda, es necesaria la introducción de un "humanismo digital" en el discurso educativo sobre las tecnologías. Algo que nos ayude a una mejor comprensión de la mutación cultural inducida por lo digital en los distintos ámbitos de la actividad humana, desde la ecología (los materiales utilizados para la fabricación de herramientas y gatgets), jurídicas y económicas (gestión de la propiedad intelectual, etc.), históricas y políticas (nuestras relaciones con el patrimonio, y el activismo hacker) todas ellas cuestiones de un gran calado ético (Doueihi, 2012). En este sentido, para nosotros y siguiendo el discurso de Doueihi, el humanismo digital se opone a las diferentes escuelas transhumanistas, poshumanistas y ciberhumanistas; e implica aceptar las mutaciones culturales introducidas por lo digital constatando la indisociabilidad que existe entre las prácticas culturales digitales y los valores que las sostienen, sin perder de vista la centralidad de la persona en el ciberespacio y en los procesos comunicacionales.

Actualmente, en el contexto de una "educación por competencias" corremos el riesgo de disolver los contenidos humanistas en una "educación" donde predominen los elementos científicos y aleja cada vez más del cuestionamiento ético de la realidad. Paradójicamente, lo que se pone de manifiesto con esta disolución es la relevancia de ciertos "intangibles pedagógicos" en al educación (García Amilburu y García Gutiérrez, 2012), donde todo afán de medición resulta superficial. En efecto, si pensamos que la educación es "algo más" que preparación para una profesión comprenderemos la existencia de ciertos elementos (intangibles pedagógicos) que pasando desapercibidos a los criterios de productividad, son esenciales e indisociables de la idea de profesionalidad a la que también se tiende desde el proceso educativo.

Por ejemplo, para la OCDE, en el centro del marco de competencias clave se encuentra la habilidad de los individuos de pensar por sí mismos como expresión de una madurez moral e intelectual, y de tomar responsabilidad por su aprendizaje y por sus acciones (DESECO, 2005). De ahí la importancia que adquieren tanto los valores como la noción de reflexión,

\footnotetext{
"Pensar reflexivamente requiere procesos mentales relativamente complejos y que el asunto se convierta en el objeto de un proceso de pensamiento. Por ejemplo, cuando se quiere dominar una técnica mental en particular, la reflexión permite a los individuos pensar después en esta técnica, asimilarla y relacionarla con otros aspectos de sus experiencias y cambiarla o adaptarla. Los individuos acostumbrados a reflexionar también siguen estos procesos de pensamiento en la práctica o en la acción. Así pues, la reflexión implica el uso de destrezas meta cognitivas (pensar acerca de pensar), habilidades creativas y la adopción de una actitud crítica. No es solamente la forma en que los individuos piensan, también cómo comprenden una experiencia de manera más general, incluyendo sus pensamientos, sentimientos y relaciones sociales. Esto requiere que los
}

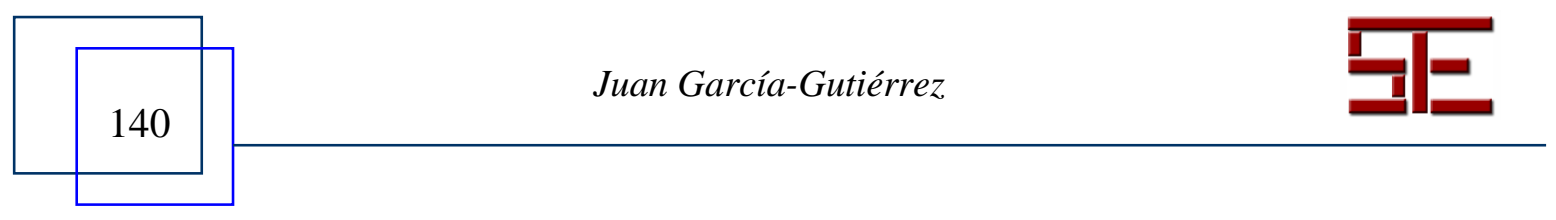




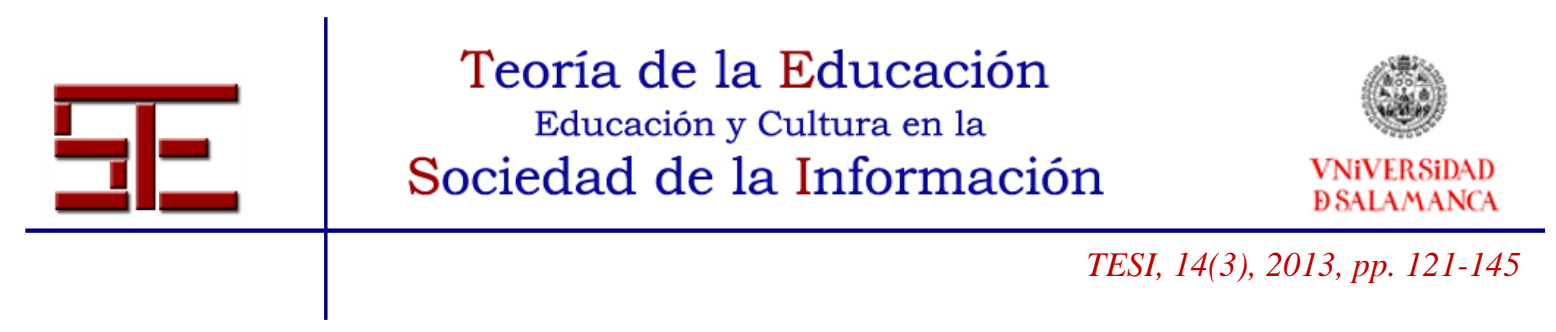

individuos alcancen un nivel de madurez social que les permita distanciarse de las presiones sociales, adoptar diferentes perspectivas, hacer juicios independientes y tomar responsabilidad por sus acciones" (DESECO, 2005, 7)

Algo que implica, en cualquier caso, una visión integral del desarrollo de la persona y de las comunidades que se nos muestran como el fin y la medida de todas las tecnologías de la información y la comunicación. Efectivamente,

\begin{abstract}
“este nuevo contexto nos emplaza hacia la superación del pensamiento instrumentalista desde el que las tecnologías se interpretan como meras herramientas que nos permiten hacer cosas, cada vez de manera más rápida o eficiente, volviéndonos más autónomos en el sentido de autosuficientes. Es decir, hasta ahora podíamos pensar en las tecnologías como un apoyo a la autonomía del sujeto, sirviéndose éste de sus usos para alcanzar una meta final. Hoy, es preciso entender las tecnologías desde otra óptica, no instrumental, y que no limite ni encapsule la idea de autonomía solo en relación a los conceptos de dependencia/independencia" (Reyero García, et. al., 2011).
\end{abstract}

En definitiva, la educación en un mundo tecnificado y virtual no puede prescindir de las competencias éticas, y de una "lógica" que sea capaz de transcender los planteamientos utilitaristas del uso hasta abrir paso a la reflexión sobre el sentido de las tecnologías y el ciberespacio como ámbitos de formación humana. Como indican García Amilburu y Ruiz Corbella $(2009,119)$, una gran parte de las capacidades y competencias que los profesionales de la educación más valoran no pueden englobarse propiamente en el mundo mercantil, sino que pertenecen más bien al ámbito humanista, y se adquieren y consolidan precisamente con el cultivo de estos saberes; "fomentando las actitudes y los conocimientos que permitirán al espíritu del hombre continuar estando abierto a la totalidad de lo real".

\title{
REFERENCIAS
}

Adell, J. (2004). Internet en educación. Comunicación y Pedagogía, 200, pp. 25-28.

Alberici, J. y Serreri, P. (2005). Competencias y formación en la edad adulta. Balance de competencias. Barcelona: Alertes

Asensio Aguilera, J. Mª at. al. (2012). Las competencias de los profesionales de la educación hoy: la transformación de la práctica educativa. En García Aretio, L. (Coord.) Sociedad del conocimiento y educación (pp. 193-213). Madrid: UNED.

Attewell, P. (2009). ¿Qué es una competencia?. Revista Interuniversitaria de Pedagogía Social, 16, 21-44.

Bautista-Cerro, M M $^{\mathrm{a}}$ J. y Melendro Estefanía, M. (2011). Competencias para la intervención socioeducativa con jóvenes en dificultad social. Educación XX1, 14, 179-200.

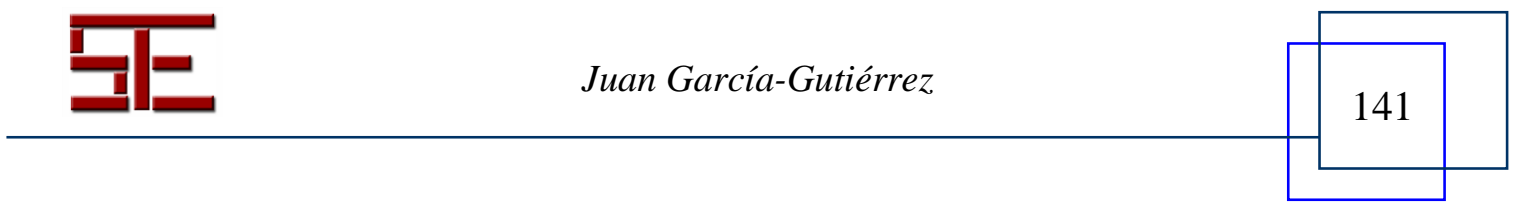




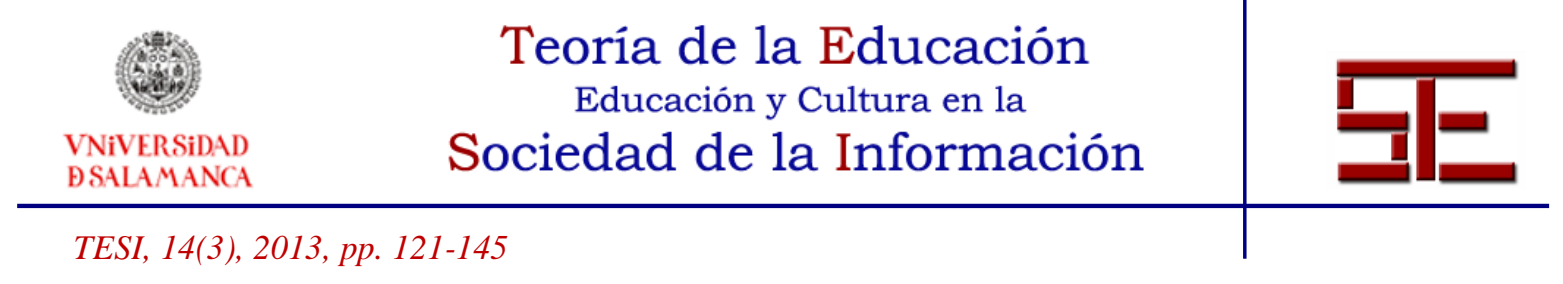

Bizquerra Alzina, R. y Perez Escoda, N. (2007). Las competencias emocionales. Educación XX1, 10, 61-82.

Burguet Arfelis, M. y Buxarrais Estrada, Ma . R. (2012). Competencias ético-digitales: transversalidad y paradojas. En García Aretio, L. (Coord.) Sociedad del conocimiento y educación (pp. 221-226). Madrid: UNED.

Bustamante Donas, J. (2001). Hacia la cuarta generación de derechos humanos: repensando la condición humana en la sociedad tecnológica. Revista Iberoamericana de Ciencia, Tecnología, Sociedad e Innovación, 1, 1-10.

CEDEFOP (2008). Terminology of European education and training policy. Luxembourg: Office for Official Publications of the European Communities.

Comisión Europea (2012). Estrategia europea en favor de una Internet más adecuada para los niños. COM 196 final, de 2 de mayo.

DESECO (2005). La definición y selección de competencias clave (resumen ejecutivo). París: OCDE.

Doueihi, M. (2012). ¿Qué es el humanismo digital?. En S. Champeau y D. Innerarity (Comps.) Internet y el futuro de la democracia (pp. 201-209). Barcelona Paidós.

Eurydice (2002). Las competencias clave. Un concepto en expansión dentro de la educación general obligatoria. Madrid: CIDE.

García Amilburu, M. y Ruiz Corbella, M. (2009). ¿Tiene futuro la filosofía de la educación en un diseño de educación en competencias?. En Ibáñez-Martín, J. A. (Coord.) Educación, conocimiento y justicia (pp. 101-126). Madrid: Dykinson.

García Amilburu, Ma . y García Gutiérrez, J. (2012). Filosofía de la educación. Cuestiones de hoy y de siempre. Madrid: Narcea.

García Gutiérrez, J. (2012). Más allá del tecnocentrismo pedagógico. En García Aretio, L. (Coord.) Sociedad del conocimiento y educación (pp. 155-159). Madrid: UNED.

Gómez Cruz, E. (2007). Las metáforas de internet. Barcelona: UOC.

Innerarity, D. (2013). Un mundo de todos y de nadie. Piratas, riesgos y redes en el nuevo desorden global. Barcelona: Paidós.

ITE (2010). Habilidades y competencias del siglo XXI para los nuevos aprendices del nuevo milenio en los países de la OCDE. Madrid: MEC.

Juanas, A. (2010). Aprendices y competencias en el Espacio Europeo de Educación Superior. Revista de Psicología y Educación, 5, 171-186.

Marina, J. A. (2009). La competencia de emprender. Revista de Educación, 351, 49-71.

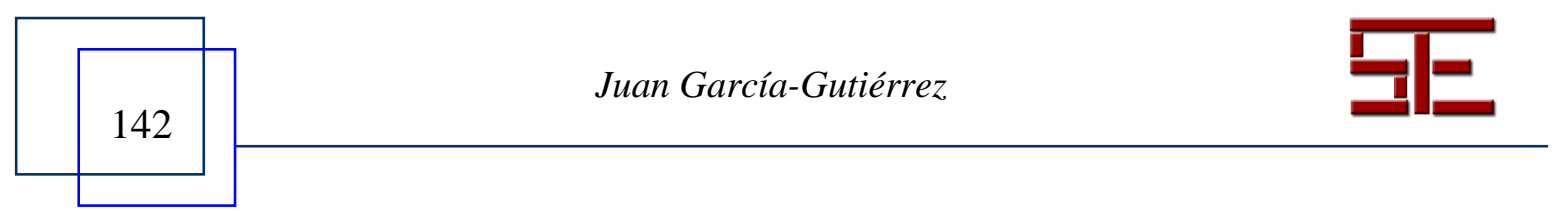




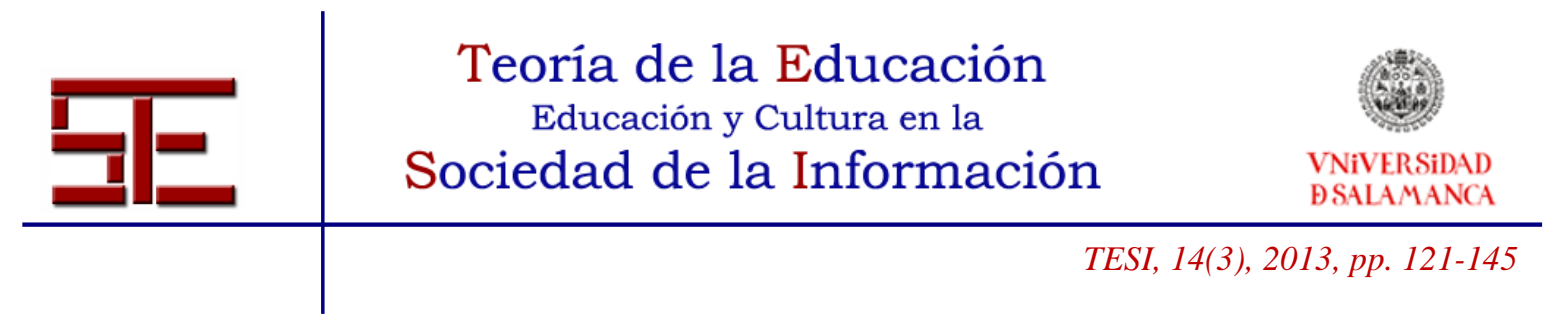

Navío Gámez, A. (2005). Propuestas conceptuales en torno a la competencia profesional. Revista de Educación, 337, 213-234.

Ortega Navas, $\mathrm{M}^{\mathrm{a}}$ C. (2010). Competencias emergentes del docente ante las demandas del espacio europeo de educación superior. Revista Española de Educación Comparada, 16, 305-327.

Pérez Herrans, F. M. (2008). Ética en el ciberespacio. Ontology Studies, 8, pp. 317-328.

Reyero García, D. Et. al. (2011). Autonomía y responsabilidad en el contexto de la sociedad de las tecnologías de la información y la comunicación. XXX Seminario Interuniversitario de Teoría de la Educación "Autonomía y responsabilidad. Contextos de aprendizaje y educación en el siglo XXI". Extraído el 15 de junio, 2013 de: http://pendientedemigracion.ucm.es/info/site/docu/30site/ponencia4.pdf

Rychen D.S. \& Salganik L.H. (Eds.) (2004). Definir y seleccionar las competencias fundamentales para la vida. México: FCE.

Sicart, M. (2012). Ética y diseño de videojuegos. En VVAA. Extra life. 10 videojuegos que han revolucionado la cultura contemporánea (pp. 271-290). Madrid: Errata naturae.

Villa Sánchez, A. y Poblete Ruiz, M. (2008). (Eds.). Competence-based learning. A proposal for the assessment of generic competences. Bilbao: University of Deusto.

\section{NOTAS}

1. Livingstone, S., Haddon, L., Görzig, A., \& Ólafsson, K. (2011). Risks and safety on the internet: The perspective of European children. Extraído el 17 de junio, 2013 de: http://www.lse.ac.uk/media@lse/research/EUKidsOnline/EU\%20Kids\%20II\%20(200911)/EUKidsOnlineIIReports/D4FullFindings.pdf

2. En este sentido hay que indicar que la mayor parte de las veces la seguridad implica un elemento externo al propio sujeto de control (y en consecuencia de falta de libertad), mientras que la responsabilidad siempre pertenece al sujeto, a su libertad y a su autonomía.

3. Vid. en las siguientes direcciones podemos encontrar este tipo de discursos: http://www.diainternetsegura.es;

https://www.obrasocialcajamadrid.es/Ficheros/CMA/ficheros/OBSSocial_GuiaUsoSaludablePrimaria. PDF; http://espanol.att.com/help/internet_safety/just_for_kids/game.html; http://ec.europa.eu/digitalagenda/en/creating-better-internet-kids

4. Este trabajo profundiza en las ideas contenidas en la addenda presentada en el XXXI Seminario Interuniversitario de Teoría de la Educación, celebrado en Plasencia, "Más allá del tecnocentrismo pedagógico" (García Gutiérrez, 2012). Igualmente es deudor de los resultados del proyecto de investigación "Retos ético-pedagógicos en entornos virtuales. Análisis de la realidad y propuestas educativas" (Grupo de Investigación "La educación como acción”. Plan propio de investigación, Desarrollo e Innovación UNIR. Convocatoria 2012-2013).

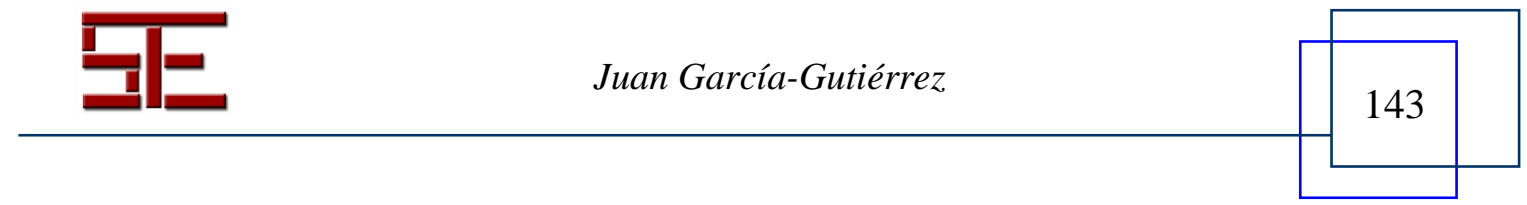




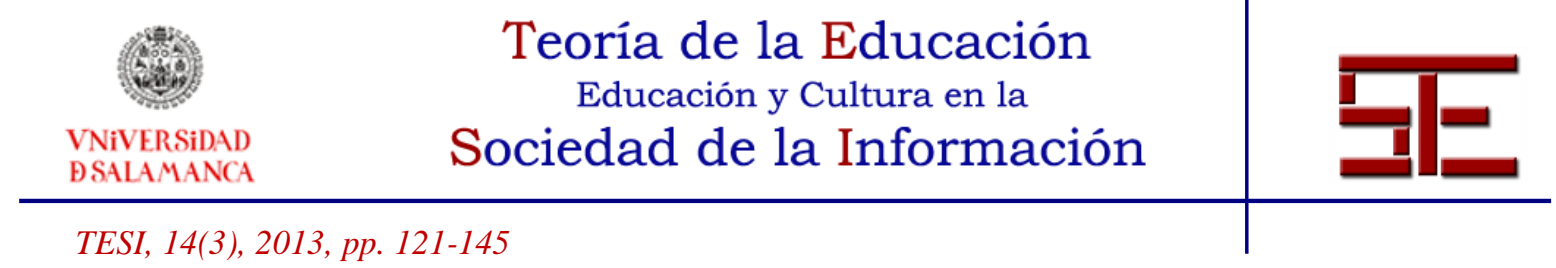

5. Es realmente significativa la introducción que aparece en el Programa de trabajo de la Comisión sobre "Competencias clave”: “(...) Para lograr esto [se refiere a los objetivos de Lisboa], los sistemas de educación y formación deben adaptarse a las demandas de la sociedad del conocimiento y a la necesidad de mejorar el nivel y la calidad del trabajo. Uno de los componentes básicos de esta propuesta es la promoción de destrezas básicas: en concreto, el Consejo Europeo de Lisboa hizo un llamamiento a los Estados Miembros al Consejo y a la Comisión para que establecieran un marco europeo que definiera "las nuevas destrezas básicas" proporcionadas por medio de un aprendizaje a lo largo de la vida. Este marco debería incluir TIC, cultura tecnológica, lenguas extranjeras, espíritu emprendedor y habilidades sociales".

6. Consejo Europeo de Lisboa (2000). Conclusiones de la Presidencia. Extraído el 17 de junio, 2013 de: http://www.consilium.europa.eu/ueDocs/cms_Data/docs/pressData/es/ec/00100-r1.es0.htm

7. Informe del Consejo de Educación al Consejo Europeo, de 14 de febrero de 2001, sobre los futuros objetivos precisos de los sistemas educativos (5680/91 EDU 18).

8. Programa de trabajo para el seguimiento de los objetivos concretos de los sistemas de educación y formación en Europa (DO C 142 de 14 de febrero de 2002).

9. Informe del Consejo de Educación al Consejo Europeo, de 14 de febrero de 2001, sobre los futuros objetivos precisos de los sistemas educativos (5680/91 EDU 18).

10. DO L 2006/962/CE, de 18 de diciembre de 2006. Seis meses más tarde, y siguiendo la Recomendación del Parlamento Europeo, el "marco de referencia europeo" era incluido en la Ley Orgánica de Educación (LOE, 2006) donde la noción de competencia adquiriría un estatus jurídicoeducativo. Estos trabajos continúan con el horizonte 2020, vid. "Conclusiones del Consejo, de 12 de mayo de 2009, sobre un marco estratégico para la cooperación europea en el ámbito de la educación y la formación" (DO C 119, de 28 de mayo de 2009).

11. Consejo Europeo de Lisboa (2000). Conclusiones de la Presidencia. Extraído el 17 de junio, 2013 de: http://www.consilium.europa.eu/ueDocs/cms_Data/docs/pressData/es/ec/00100-r1.es0.htm

12. Vid. Comunidades Europeas. Dirección General de Educación y cultura (2009). Marco europeo de cualificaciones para el aprendizaje permanente. Luxemburgo: Oficina de publicaciones.

13. Vid. Tuning Education Structures in Europe. Extraído el 15 de junio, 2013 de: http://www2.relint.deusto.es/servlet/Satellite/Page/1234362756092/_cast/

14. Vid. ANECA (2005). Libro blanco del título de Grado en Pedagogía y Educación Social. Extraído el 17 de junio, 2013 de: http://www.aneca.es/var/media/150392/libroblanco_pedagogia1_0305.pdf

15. Una aplicación interesante la encontramos en el caso de los videojuegos en M. Sicart (2012).

16. Vid. Bustamante Donas, J. (2001). Hacia la cuarta generación de Derechos Humanos: repensando la condición humana en la sociedad tecnológica. Revista Iberoamericana de Ciencia, Tecnología, Sociedad e Innovación, 1. Extraído el 15 de junio, 2013 de: http://www.oei.es/revistactsi/numero1/bustamante.htm

17. Este estudio forma parte del proyecto "Retos ético-pedagógicos en entornos virtuales. Análisis de la realidad y propuestas educativas" (Grupo de Investigación "La educación como acción”. Plan propio de investigación, Desarrollo e Innovación UNIR. Convocatoria 2012-2013). Una visión más completa del estudio (objetivos, muestras, metodología, etc.) y de los resultados aparece en García Gutiérrez, J.; Moreno, D. y Plaza, J. (2013) Expectations and forms of ownership of the technology by compulsory secondary education teachers, en Iadat Conference Proceedings "Innovation, Technology and Research in Higher Education, pp. 60-64. Bilbao: IADAT.

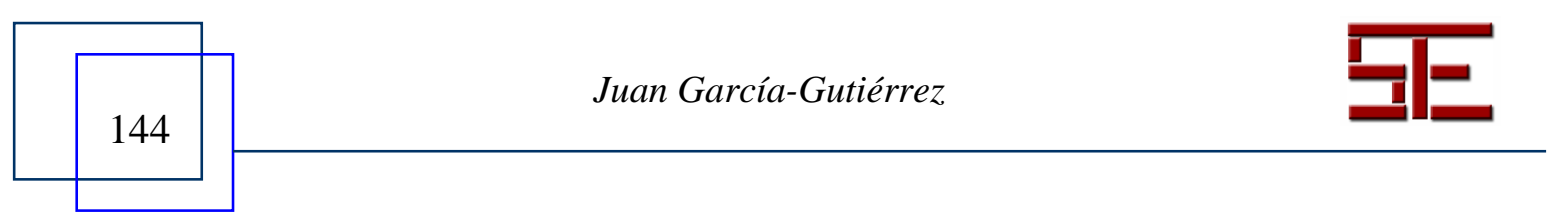




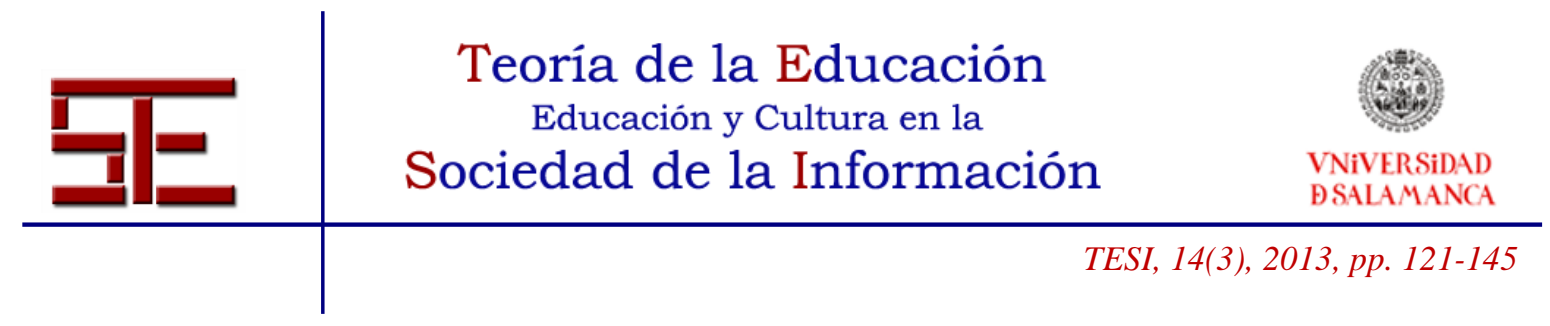

18. Vid. "Survey of Schools: ICT in Education. Benchmarking Access, Use and Attitudes to Technology in Europe's Schools". Extraído el 15 de junio, 2013 de: https://ec.europa.eu/digitalagenda/sites/digital-agenda/files/KK-31-13-401-EN-N.pdf.

Para citar el presente artículo puede utilizar la siguiente referencia:

García-Gutiérrez, J. (2013). Aproximación ética a la competencia digital. Los niveles de uso y sentido en ámbitos educativos virtuales. Revista Teoría de la Educación: Educación y Cultura en la Sociedad de la Información. 14(3), 121-145 [Fecha de consulta: $\mathrm{dd} / \mathrm{mm} / \mathrm{aaaa}]$.

http://campus.usal.es/ revistas_trabajo/index.php/revistatesi/article/view/11354/11771

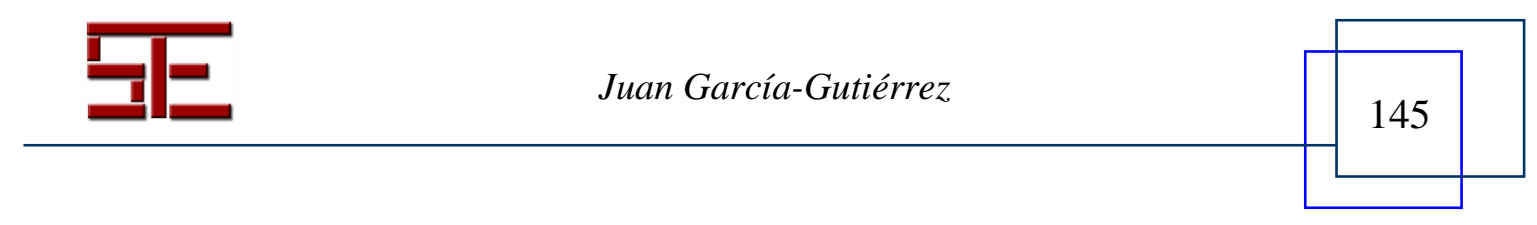

